\title{
WAVES, CURRENTS, SEDIMENT FLUX AND MORPHOLOGICAL RESPONSE IN A BARRED NEARSHORE SYSTEM
}

\author{
BRIAN GREENWOOD and DOUGLAS J. SHERMAN*
}

Departments of Geography and Geology, Scarborough Campus, University of Toronto, Scarborough, Ont. M1C 1 A4 (Canada)

Department of Geography, Scarborough Campus, University of Toronto, Scarborough, Ont. M1C $1 A 4$ (Canada)

(Received April 16, 1983; revised and accepted August 31, 1983)

\section{ABSTRACT}

Greenwood, B. and Sherman, D.J., 1984. Waves, currents, sediment flux and morphological response in a barred nearshore system. In: B. Greenwood and R.A. Davis, Jr. (Editors), Hydrodynamics and Sedimentation in Wave-Dominated Coastal Environments. Mar. Geol., 60: 31-61.

A shore-normal array of seven, bi-directional electromagnetic flowmeters and nine surface piercing, continuous resistance wave staffs were deployed across a multiple barred nearshore at Wendake Beach, Georgian Bay, Canada, and monitored for a complete storm cycle. Time-integrated estimates of total (ITVF) and net (INVF) sediment volume flux together with bed elevation changes were determined using depth-of-activity rods.

The three bars, ranging in height from 0.10 to $0.40 \mathrm{~m}$ accreted during the storm $(0.03 \mathrm{~m})$, and the troughs were scoured $(0.05 \mathrm{~m})$. Sediment reactivation depths reached $0.14 \mathrm{~m}$ and $12 \%$ of the nearshore control volume was mobilized. However, the INVF value for the storm was less than $1 \%$ of the control volume revealing a near balance in sediment volume in the bar system. Landward migration of the inner, crescentic and second, sinuous bars occurred in association with an alongshore migration of the bar form itself; the outermost, straight, shore-parallel bar remained fixed in location.

The surf zone was highly dissipative throughout the storm $\left(\epsilon=3.8 \times 10^{2-1}-192 \times 10^{2}\right)$ and the wave spectrum was dominated by energy at the incident frequency. Spectral peaks at frequencies of the first harmonic and at one quarter that of the incident wave were associated with secondary wave generation just prior to breaking and a standing edge wave, respectively. The former spectral peak was within the $95 \%$ confidence band for the spectrum while the latter contributed not more than $10 \%$ to the total energy in the surface elevation spectrum even near the shoreline.

During the storm wave height exceeded $2 \mathrm{~m}\left(H_{\mathrm{s}}\right)$ and periods reached $5 \mathrm{~s}\left(T_{\mathrm{pk}}\right)$ : orbital velocities exceeded $0.5 \mathrm{~m} \mathrm{~s}^{-1}\left(u_{\mathrm{rms}}\right)$ and were above the threshold of motion for the medium-to-fine sands throughout the storm. Shore-parallel flows in excess of $0.4 \mathrm{~m} \mathrm{~s}^{-1}$ were recorded with maxima in the troughs and minima just landward of the bar crest.

The rate and direction of sediment flux is best explained by the interaction of antecedent bed slopes with spatial gradients in the mean and asymmetry of the shore-normal velocity field. These hydrodynamic parameters represent "steady" flows superimposed on the dominantly oscillatory motion and assumed a characteristic spatial pattern from the

\footnotetext{
*Present address: Department of Geography, University of Southern California, Los Angeles, CA 90007 , U.S.A.
} 
storm peak through the decay period. Increases spatially in the magnitudes of both the mean flows and flow asymmetries cause an increasing net transport potential (erosion); decreases in these values spatially cause a decreasing net transport potential and thus deposition. These transport potentials are increased or decreased through the gravity potential induced by the local bed slope. Shore-parallel flow was important in explaining sediment flux and morphological change where orbital velocities, mean flows and flow asymmetries were at a minimum.

\section{INTRODUCTION}

Since the first scientific description of wave-formed bars by Elie de Beaumont in 1845, considerable effort has been devoted to understanding their origins and dynamics. A large literature exists on the morphology, and more recently the sedimentology, of these ubiquitous geomorphological features. Many questions remain, however, concerning the complex interactions between the nearshore fluid and sediment motions, and the topography itself (for a review see Greenwood and Davidson-Arnott, 1979; and Greenwood, 1982). Knowledge of these interactions is important, since bars frequently form stable, equilibrium, bathymetric configurations in a wide range of coastal environments, often under conditions of high alongshore sediment transport (Greenwood and Davidson-Arnott, 1979; Greenwood and Mittler, 1984, this volume). In other places, in contrast, bars are formed and destroyed as conditions change (Goldsmith et al., 1982; Bowman and Goldsmith, 1983).

Most studies of the hydrodynamics and sediment dynamics of barred nearshores have been restricted to theoretical and laboratory research with the associated problems of scale in the latter. Only recently has instrumentation been available allowing comprehensive experiments in the prototype, capable of providing data for the testing of theoretical models. Since sediment flux and bar morphodynamics are a direct response to wave-induced currents and since the latter (at least at present) are the more easily measured, then examination of such fluid motions should provide insights into sediment and bar dynamics. This paper documents an experiment designed to monitor the incident and secondary wave characteristics, wave-induced orbital and shoreparallel flows, and the local sedimentary response during a single storm event in a barred nearshore in the Canadian Great Lakes.

\section{LOCATION OF STUDY}

The study site is at Wendake Beach in Southern Georgian Bay, Ontario (Fig.1). It is tideless, and waves are generated over discrete time intervals during the passage of meteorological depressions, causing rapid changes in the magnitude and direction of incident wave energy. Fetch lengths vary, with maxima to the WNW $(84 \mathrm{~km})$ and $W(51 \mathrm{~km})$. With limited fetch and local storm winds, wind forcing of the waves is continuous to the shoreline under most wave states.

In the Wendake Beach system 3 bars are present on a mean slope of 0.015 in medium to fine sands $(0.43-0.13 \mathrm{~mm}$ mean diameter $)$. The outer bar is 


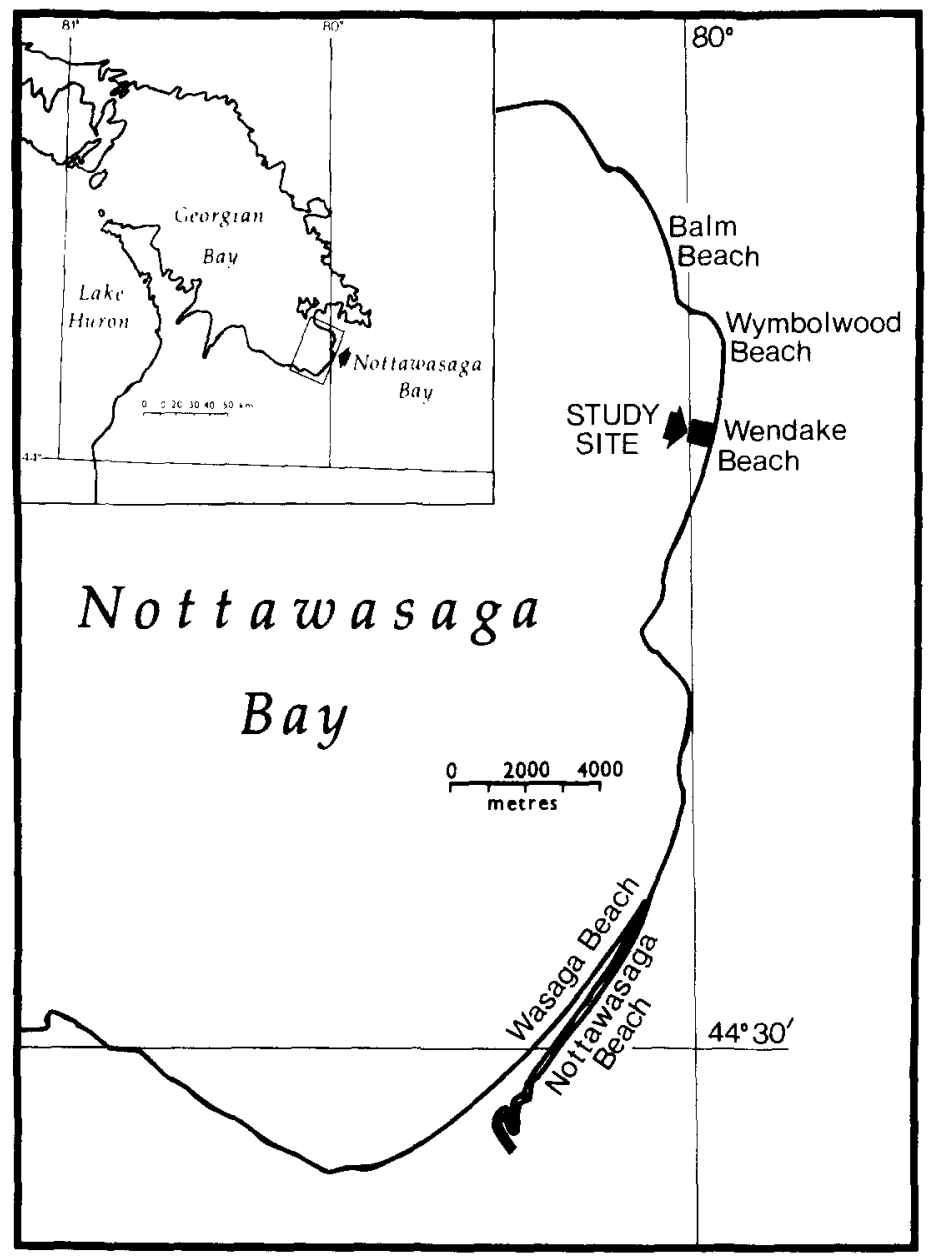

Fig.1. Location of study area.

$110 \mathrm{~m}$ from the shoreline, approximately $0.50 \mathrm{~m}$ high, relatively straight, near-symmetrical and shore-parallel (Fig.2). The inner bars, at approximately 54 and $10 \mathrm{~m}$ from the shoreline, respectively, range in height from 0.10 to $0.35 \mathrm{~m}$ and are asymmetrical in section and sinuous to crescentic in planform. There is a reduction in spacing of the bars landward and, although some alongshore periodicity in form is evident in the inner bars, it is difficult to isolate: the dominant periodicity in form is in the shore-normal direction and thus the process(es) controlling sedimentation are most probably periodic in the same direction. While the bars are distinct bathymetric configurations, the nearshore slope deviates little from a planar configuration: a least squares linear fit explains more than $90 \%$ of the observed variance in relief. 


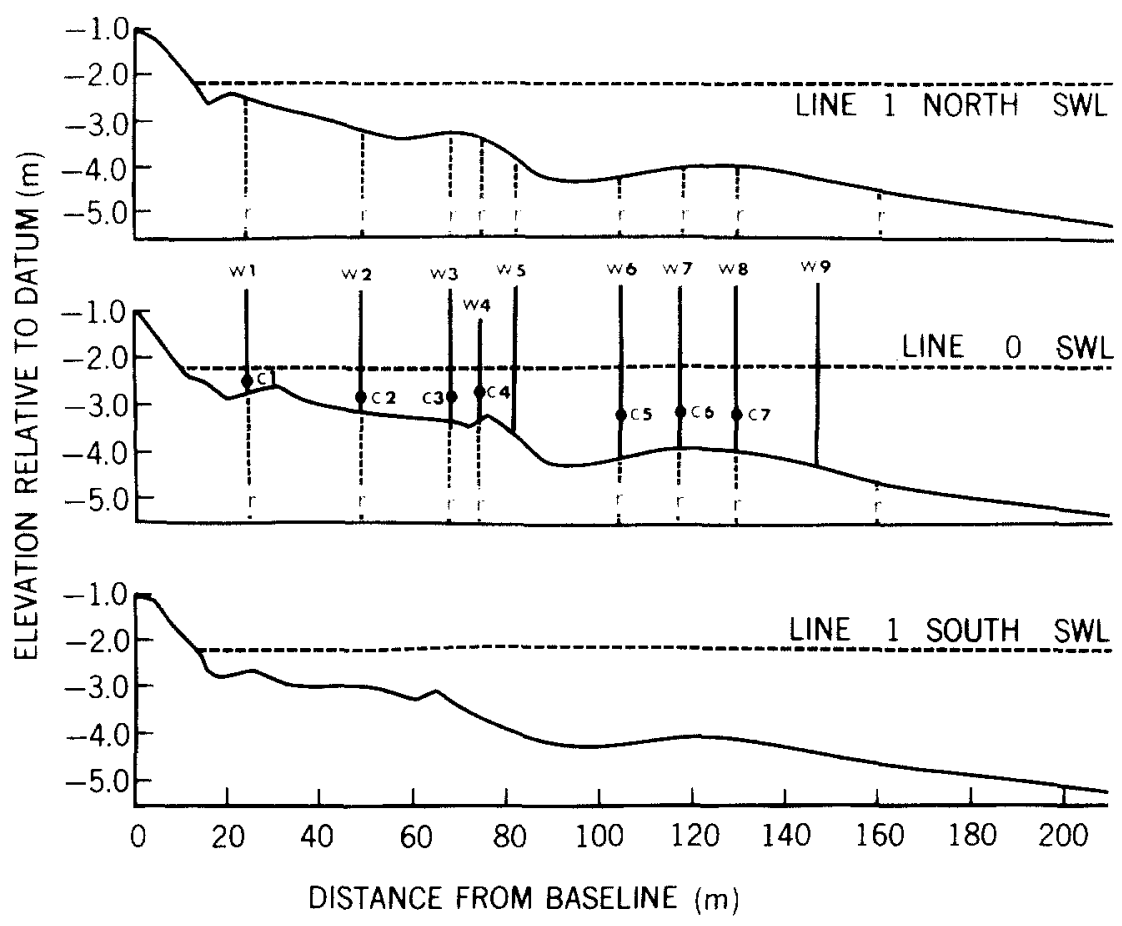

Fig. 2. Nearshore profiles and instrument deployment prior to the storm, Wendake Beach, 1980:05:31. Line zero is the instrument array transect; lines 1 North and 1 South are spaced $30 \mathrm{~m}$ either side of the zero line. $W=$ wave wire; $C=$ current meter; $r=$ depth of activity rod. Note that along the instrument transect the depth of activity rods were offset $1 \mathrm{~m}$ to avoid interference by the wave wire supports.

\section{EXPERIMENTAL DESIGN}

The field experiment was designed specifically to examine the twodimensional nature of the nearshore hydrodynamics and sedimentation in a plane normal to the shoreline. It involved the deployment of a shore-normal array of wave and current sensors cable-linked to a high-speed data acquisition and mass storage system. Morphological changes were monitored using conventional profiling with level and staff in shallow water and echo sounding offshore; more detailed measurements of sediment flux and bed elevation change were made using depth-of-activity rods. More detail on the fluid monitoring system can be found in Greenwood (1982) and Greenwood and Sherman (1983); the depth-of-activity rods are described fully in Greenwood and Hale (1980), Greenwood et al. (1980) and Greenwood and Mittler (1984, this volume). Only a synopsis of methods will be presented here.

\section{Wave and current sensors}

Two types of instruments were used to monitor the fluid motions. Water surface elevation changes associated with waves were measured by surface 
piercing, continuous resistance wave staffs following the basic design of Truxillo (1970). Helically wound, steel wires set in 2 or $3 \mathrm{~m}$ long, 18.8 $\mathrm{mm}$ diameter PVC pipes were mounted by insulated brackets on $37.5 \mathrm{~mm}$ galvanized steel pipes. The latter were mounted on two metre long bases jetted into the bed. Staffs were field calibrated individually to specific oscillator-detector circuits and were linear except for the lowermost $0.25 \mathrm{~m}$.

Shore-normal and shore-parallel horizontal flows were monitored using biaxial electromagnetic flow meters designed by Marsh-McBirney. These instruments have a time constant of $0.2 \mathrm{~s}$ and measure flows up to $3 \mathrm{~m} \mathrm{~s}^{-1}$. Considerable work on the accuracy of these meters has been undertaken (see review of Huntley, 1980) and, while some problems still exist, the level of accuracy is thought to be significantly better than $10 \%$. The meters were mounted in a specially designed bracket that allowed rotation in both the vertical and horizontal planes for accurate orientation of the probes. This assembly was mounted on a stainless steel support. A galvanized steel pipe, with fin to prevent rotation, was jetted into the bed to provide the base support.

Figure 2 documents the instrument locations during the experiment. Of particular importance were the locations of the current meters, since near-bed flows were to be related to sediment transport. Unfortunately our knowledge of the structure of turbulent oscillatory boundary layers over rough beds is still rudimentary, especially with respect to combined waves and currents (see Grant and Madsen, 1979). In any case the thickness of the bottom boundary layer will be highly variable depending upon local flow and bed roughness conditions. With the necessity of a fixed position in the shallow water depths of the Wendake Beach surf zone, and the likelihood of a logarithmic law being important even in the oscillatory boundary layer (Jonsson, 1980) it was decided to place the sensors at the same relative water depth $(h / 2)$ in all cases. In this way at least the same segment of the water column was monitored.

\section{Data acquisition and analysis}

All sensors were hardwired to the shore-based data acquisition system, which consisted of a mini-computer controlled, high-speed multiplexer and voltmeter giving potential analogue-to-digital conversion rates up to 1000 channel readings per second. Typically the instrument array was scanned every $0.5 \mathrm{~s}$ over a period of $9 \mathrm{~min}$ and the data stored on magnetic tapes. Record lengths were, of necessity, short to maintain time series stationarity in such a volatile environment. This did, however, restrict the scale of any low-frequency effects which could be detected.

The 1100 data points per sensor per sampling were truncated to 1024 points for spectral analysis and the computation of descriptive statistics, using Biomedical Computer Packages (BMDO3T and BMDP2D), after Dixon (1971) and Dixon and Brown (1979). Wave and current spectra were computed with a unit bandwidth of $0.016 \mathrm{~Hz}$ (64 lags), a detrended but unfiltered time series, 
and a fast fourier transformation to determine the spectral densities. Phase and coherence of cross spectra were also calculated. Simple descriptive statistics of the velocity field were computed using moments: for on-offshore, for example:

Mean $=\bar{u}=\frac{1}{N} \sum_{i=1}^{N} u_{i}$

Standard deviation $=u_{\mathrm{rms}}=\left[\frac{1}{N} \sum_{i=1}^{N}\left(u_{i}-\bar{u}\right)^{2}\right]^{1 / 2}$

Skewness $=u_{\mathrm{sk}}=\frac{1}{N} \sum_{i=1}^{N}\left(u_{i}-\bar{u}\right)^{3} /\left(u_{\mathrm{rms}}\right)^{3 / 2}$

where $u$ is the on-offshore velocity and $N$ the sample size.

\section{Monitoring sediment flux and local morphological response}

Although sediment monitoring equipment has advanced rapidly recently, no single instrument can accurately measure both suspended load and bedload and associated bed elevation changes on a continuous basis. A simple, welltested technique is used in this study to estimate sediment flux and morphological response. This involves depth-of-activity rods: these are 1 or $2 \mathrm{~m}$ long steel rods $(0.5 \mathrm{~cm}$ diameter $)$ with a free sliding washer that migrates vertically down the rod during sediment erosion and is buried at the reactivation limit by any subsequent deposition. Measurements by Scuba divers are taken prior to and at the end of the transport event to record the thickness of the active layer and the bed elevation changes. This allows estimates to be made of the time-integrated total and net volume flux through a storm as well as the net bed elevation changes for a series of discrete points. At Wendake Beach, depth-of-activity rods were deployed across the nearshore zone at the locations shown in Fig.2. Owing to incomplete installation prior to the storm, only bed elevation changes were recorded along line 0 (the instrument transect), but both depth-of-activity and bed elevation changes were recorded along line IN.

\section{WAVE-GENERATED CURRENTS AND SEDIMENT TRANSPORT POTENTIAL}

Sediment motion in the nearshore bars must be related to both shorenormal currents induced directly by primary wave oscillations, and to shoreparallel currents (longshore currents) resulting from the radiation stress associated with wave breaking and additional stresses induced by wind and alongshore pressure gradients. Secondary waves such as leaky mode or edge waves may be superimposed on these primary components. Since orbital velocities under waves are generally larger than any unidirectional current 
within the surf zone, the component of boundary shear stress due to waves will be significantly greater (Grant and Madsen, 1979) and therefore most important in the initiation of sediment movement. However, waves are inefficient transporters of sediment unless the oscillation is asymmetrical and/or combined with a superimposed current. Since the primary periodicity in sediment accumulation is normal to shore at Wendake Beach, then transport by shore-normal currents induced by primary and secondary waves is likely of greatest importance in both bar generation and maintenance in this system.

Waves within the nearshore are reasonably approximated using linear wave theory, where sinusoidal water motion is implicit (e.g. Gaughan and Komar, 1975). Waves in the surf zone, however, are markedly non-linear and water motions no longer symmetric. Sediment transport in this zone will be a function not only of the absolute velocity near the bed (a function of wave height), but also the frequency distribution of the velocity vectors. Of paramount importance in the oscillatory flow field, where the range of magnitudes of current vectors is large, is the asymmetry of the distribution of these current vectors, since sediment transport is not related linearly to the velocity, but more probably to the cube or fourth power of the absolute velocity. Quite small asymmetries can therefore be more important than any net (Lagrangian type) steady drift, even where the latter may be quite high. The importance of this was clearly recognized by Inman and Bagnold (1963), Inman and Frautschy (1966) and Wells (1967) and most recently in the transport models proposed by Bowen (1980), Bailard (1981) and Bailard and Inman (1981).

STORM EVENT 1980: 05:31-1980:06:01

Figure 3 illustrates the temporal pattern of wind speed and direction and the angle of wave approach through the storm. Storm waves were initiated by $1500 \mathrm{~h}$ (EDST) on May 31 with winds of $3 \mathrm{~m} \mathrm{~s}^{-1}$ from the WSW, which increased to a maximum of $8 \mathrm{~m} \mathrm{~s}^{-1}$ from the $\mathrm{W}$ at $2200 \mathrm{~h}$. With the passage of the frontal system, winds veered to the $\mathrm{NW}$ at $2230 \mathrm{~h}$ reaching speeds of $7 \mathrm{~m} \mathrm{~s}^{-1}$; a gradual reduction in speed occurred as a further switch to the $\mathrm{N}$ took place at $0320 \mathrm{~h}$. The storm winds dropped below $3 \mathrm{~m} \mathrm{~s}^{-1}$ at $0650 \mathrm{~h}$ as the winds backed towards the westerly direction again and the storm ended by $1015 \mathrm{~h}$ on June 1 . This dramatic change in wind and wave direction is typical of the passage of meteorological depressions in this region.

\section{Incident and secondary waves}

The general pattern of growth of the incident wave spectrum is best illustrated by characteristics measured at wave wire nine at the lakeward margin of the three-bar-system (see Fig.2). It should be stressed, however, that during the storm peak, the surf zone width reached some distance to lakeward; theory indicated that depth controlled breaking occurred up to $229 \mathrm{~m}$ from the shoreline at this time. 

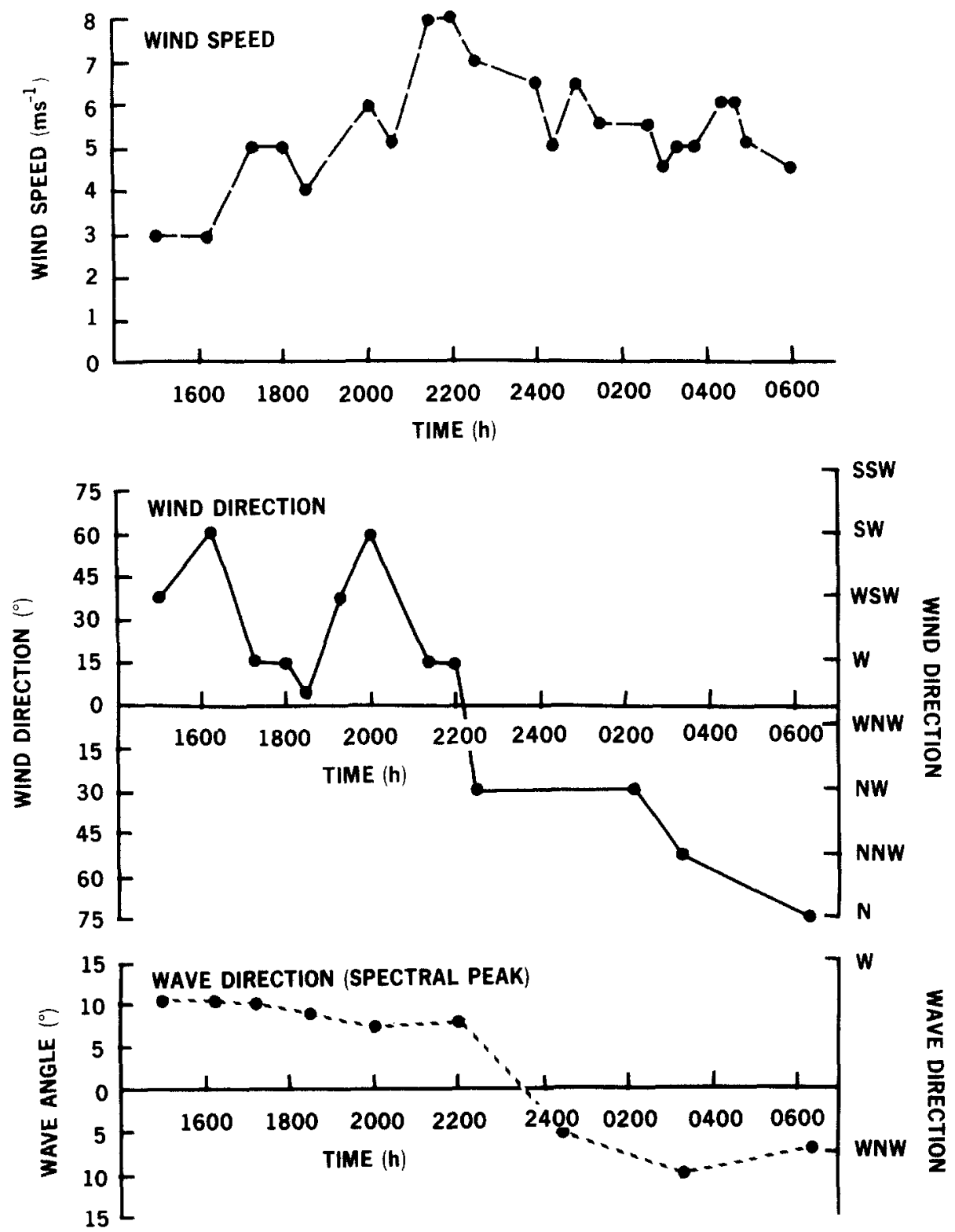

Fig. 3. Wind speed, direction and angle of wave approach to the shore normal, Wendake Beach, 1980:05:31:15:00-1980:06:01:10:15.

\section{Wave heights, periods and directions of approach}

Table I summarizes the important incident wave parameters. Significant wave heights in excess of $2 \mathrm{~m}$ and with periods of $5 \mathrm{~s}$ occurred at the storm peak. Spilling breakers were the dominant wave form, with most intense breaking on the bar crests. Although wave reformation did occur in the 
TABLE I

Incident wave parameters, Wendake Beach, 1980:05:31-06:01

\begin{tabular}{|c|c|c|c|c|c|c|c|}
\hline \multirow{2}{*}{$\begin{array}{l}\text { Time } \\
\text { (h) }\end{array}$} & \multicolumn{2}{|c|}{ Heigh $t^{1}$} & \multirow{2}{*}{$\begin{array}{l}\text { Period } \\
T_{\text {pk }} \\
\text { (s) }\end{array}$} & \multirow{2}{*}{$\begin{array}{l}\text { Angle } \\
\theta \\
\left.{ }^{\circ}\right)\end{array}$} & \multirow{2}{*}{$\begin{array}{l}\text { Breaker }{ }^{3} \text { index } \\
B_{\mathrm{b}}\end{array}$} & \multirow{2}{*}{$\begin{array}{l}\text { Scaling }{ }^{4} \text { parameter } \\
\epsilon \\
\left(\times 10^{2}\right)\end{array}$} & \multirow{2}{*}{$\begin{array}{l}\text { Surf zone }{ }^{5} \text { width } \\
X_{b} \\
(m)\end{array}$} \\
\hline & $\begin{array}{l}H_{\mathrm{rms}} \\
(\mathrm{m})\end{array}$ & $\begin{array}{l}H_{\mathrm{s}} \\
(\mathrm{m})\end{array}$ & & & & & \\
\hline 1500 & 0.59 & 0.82 & 3.4 & 10 & $0.40-0.56$ & 8 & 74 \\
\hline 1615 & 0.68 & 0.95 & 3.4 & 10 & $0.46-0.64$ & 6.5 & 124 \\
\hline 1715 & 0.76 & 1.06 & 4.0 & 10 & $0.37-0.52$ & 6.4 & 143 \\
\hline 1830 & 0.85 & 1.19 & 2.3 & 9 & $1.26-1.76$ & 192 & 133 \\
\hline 2000 & 0.78 & 1.09 & 4.3 & 7 & $0.33-0.46$ & 5.9 & 127 \\
\hline 2200 & 1.52 & 2.12 & 5.0 & 8 & $0.48-0.67$ & 5.9 & 202 \\
\hline 0025 & 0.98 & 1.37 & 5.0 & 5 & $0.31-0.43$ & 4.8 & 190 \\
\hline 0320 & 0.76 & 1.06 & 5.0 & 10 & $0.24-0.33$ & 3.8 & 142 \\
\hline 0620 & 0.62 & 0.87 & 4.0 & 6 & $0.30-0.43$ & 4.8 & 121 \\
\hline
\end{tabular}

${ }^{1}$ Wave heights determined from the total variance of the record; ${ }^{2}$ angle based upon measured orbital vector (after Sherman, 1983); ${ }^{3}$ Breaker Index, $B_{\mathrm{b}}=H_{\mathrm{b}} / \mathrm{gm} T^{2}$ (after Galvin, 1972) where beach slope $(m)=0.013$ and values for both $H_{\mathrm{rms}}$ and $H_{\mathrm{s}}$ are shown; ${ }^{4}$ Scaling Parameter $(\epsilon)=a_{\mathrm{b}} \omega^{2} / g \tan ^{2} \mathrm{~m}$ (after Guza and Inman, 1975) where $a_{\mathrm{b}}$ is taken as the rootmean-square amplitude at breaking following Wright et al. (1979); ${ }^{3}$ estimated based upon solitary wave breaking criterion $\left(\alpha_{\mathbf{b}}=0.78\right)$.

troughs observations indicated that during the storm peak and well into the decay period the whole of the surf zone was saturated with spilling breakers propagating across the troughs. Plunging breakers were occasionally observed on the second bar during the later stages of the storm and only rarely were true bores developed, occurring within a few metres of the beach face. Waves dissipated finally by collapsing at the foot of the beach.

The surf zone was in a highly dissipative state at all times and the scaling parameter (Table I) varied over two orders of magnitude. Large angles of wave approach $\left(5^{\circ}-10^{\circ}\right)$ throughout the storm (Fig.3) gave rise to significant shore-parallel currents.

\section{WAVE AND CURRENT SPECTRA}

Figure 4 indicates the form and temporal changes evident in the incident spectra. In an environment such as this, where wind forcing is continuous into the surf zone, the spectra exhibit considerable energy at a wide range of frequencies above the peak. In all cases the latter is marked by a very sharp truncation at the lower frequency end. As expected, spectral growth was accompanied by a consistent shift in the spectral peak to lower frequencies (Fig.4a and b), which remained right through the decay phase.

During the most intense part of the storm a markedly bimodal spectrum appeared (Fig.4b), with a second peak at twice the frequency of the incident peak. Energy at this frequency (the first harmonic) has long been recognized in active surf zones. It can appear as an artifact of harmonic analysis of the strongly non-linear wave form, but also through the generation of secondary waves as very rapid shoaling and energy conservation takes place just prior to 
40
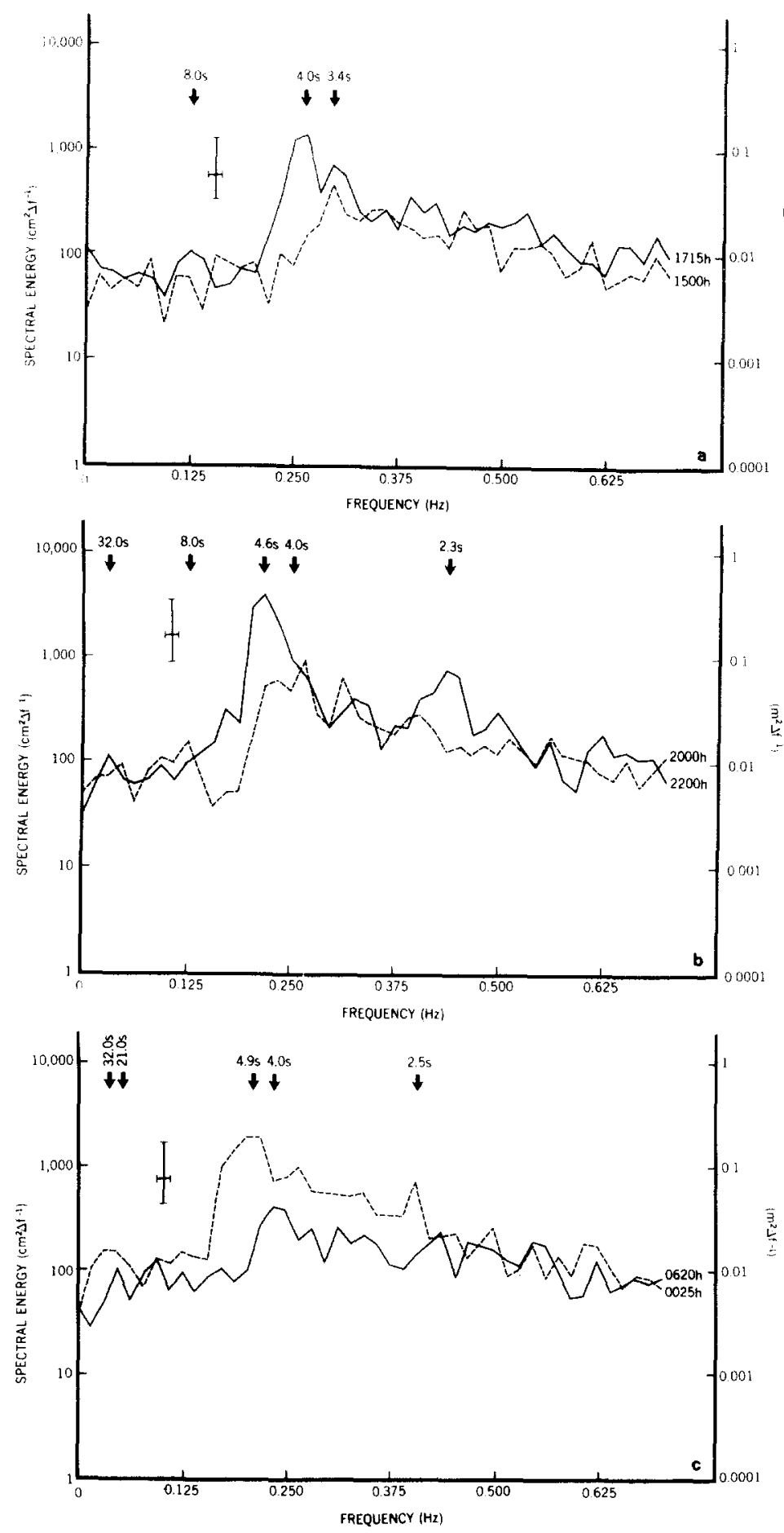
breaking (Thornton et al., 1974). The presence of secondary waves at this frequency was confirmed in the surface elevation analogue record (see also Davidson-Arnott and Randall, 1984, this volume), but overall the energy at this frequency was low (Table II).

There is very little evidence at the outer limits of the surf zone for structure in the spectra at frequencies lower than that of the incident waves (Fig.4), although under highly dissipative conditions many workers have noted a dominance of low-frequency energy (e.g. Holman et al., 1978; Holman, 1981; Wright etal., 1982). At Wendake this may reflect the distance offshore of wave wire $9(136 \mathrm{~m})$. Examination of spectra closer inshore (wave wire 4,65 m offshore; see Fig.2) reveals an energy peak at a frequency one fourth that of the incident wave (Fig.5). It was, however, statistically significant only at the peak of the storm but remained significant until the very end. It was associated with a highly dissipative state (Table I) and the largest incident wave heights and periods. It does not, however, contribute more

\section{TABLE II}

Contributions of differing frequencies of oscillation to shore-normal and shore-parallel flows in the surf zone, Wendake Beach, 1980:01:00:25

\begin{tabular}{|c|c|c|c|}
\hline \multirow{2}{*}{$\begin{array}{l}\text { Location offshore } \\
\text { (m) }\end{array}$} & \multirow{2}{*}{$\begin{array}{l}\text { Frequency } \\
(\mathrm{Hz})\end{array}$} & \multicolumn{2}{|l|}{ Current speeds* } \\
\hline & & $\begin{array}{l}\text { Shore-normal flows } u_{\text {rms }} \\
\left(\mathrm{cm} \mathrm{s}^{-1}\right)\end{array}$ & $\begin{array}{l}\text { Shore-parallel flows } v_{\mathrm{rms}} \\
\left(\mathrm{cm} \mathrm{s}^{-1}\right)\end{array}$ \\
\hline 14 & $\begin{array}{l}0.188 \\
0.047\end{array}$ & $\begin{array}{l}4.2 \\
5.0\end{array}$ & $\begin{array}{l}4.4 \\
5.4\end{array}$ \\
\hline 38 & $\begin{array}{l}0.188 \\
0.047\end{array}$ & $\begin{array}{l}8.0 \\
4.5\end{array}$ & $\begin{array}{l}5.6 \\
3.2\end{array}$ \\
\hline 57 & $\begin{array}{l}0.188 \\
0.047\end{array}$ & $\begin{array}{l}8.7 . \\
5.5\end{array}$ & $\begin{array}{l}4.4 \\
2.6\end{array}$ \\
\hline 64 & $\begin{array}{l}0.188 \\
0.047\end{array}$ & $\begin{array}{r}12.0 \\
4.5\end{array}$ & $\begin{array}{l}3.6 \\
3.4\end{array}$ \\
\hline 94 & $\begin{array}{l}0.188 \\
0.047\end{array}$ & $\begin{array}{l}8.3 \\
2.6\end{array}$ & $\begin{array}{l}2.7 \\
1.5\end{array}$ \\
\hline 106 & $\begin{array}{l}0.188 \\
0.047\end{array}$ & $\begin{array}{l}8.7 \\
2.8\end{array}$ & $\begin{array}{l}3.1 \\
1.3\end{array}$ \\
\hline 118 & $\begin{array}{l}0.188 \\
0.047\end{array}$ & $\begin{array}{r}10.2 \\
3.6\end{array}$ & $\begin{array}{l}2.6 \\
1.3\end{array}$ \\
\hline
\end{tabular}

Simple calculations based upon variances over one unit bandwidth at the respective spectral peaks. The peaks were identified using surface elevation spectra.

Fig.4. Wave spectra at outer margin of the surf zone through the early part of the storm (a), during the storm peak (b) and during the period of storm decay from the peak (c). These and all following spectra are based on 1024 data points. Unit bandwidth is $0.016 \mathrm{~Hz}$ and is given by the horizontal bar: the $95 \%$ confidence band around the spectral estimates is given by the vertical bar. All spectra have $32^{\circ}$ of freedom. 

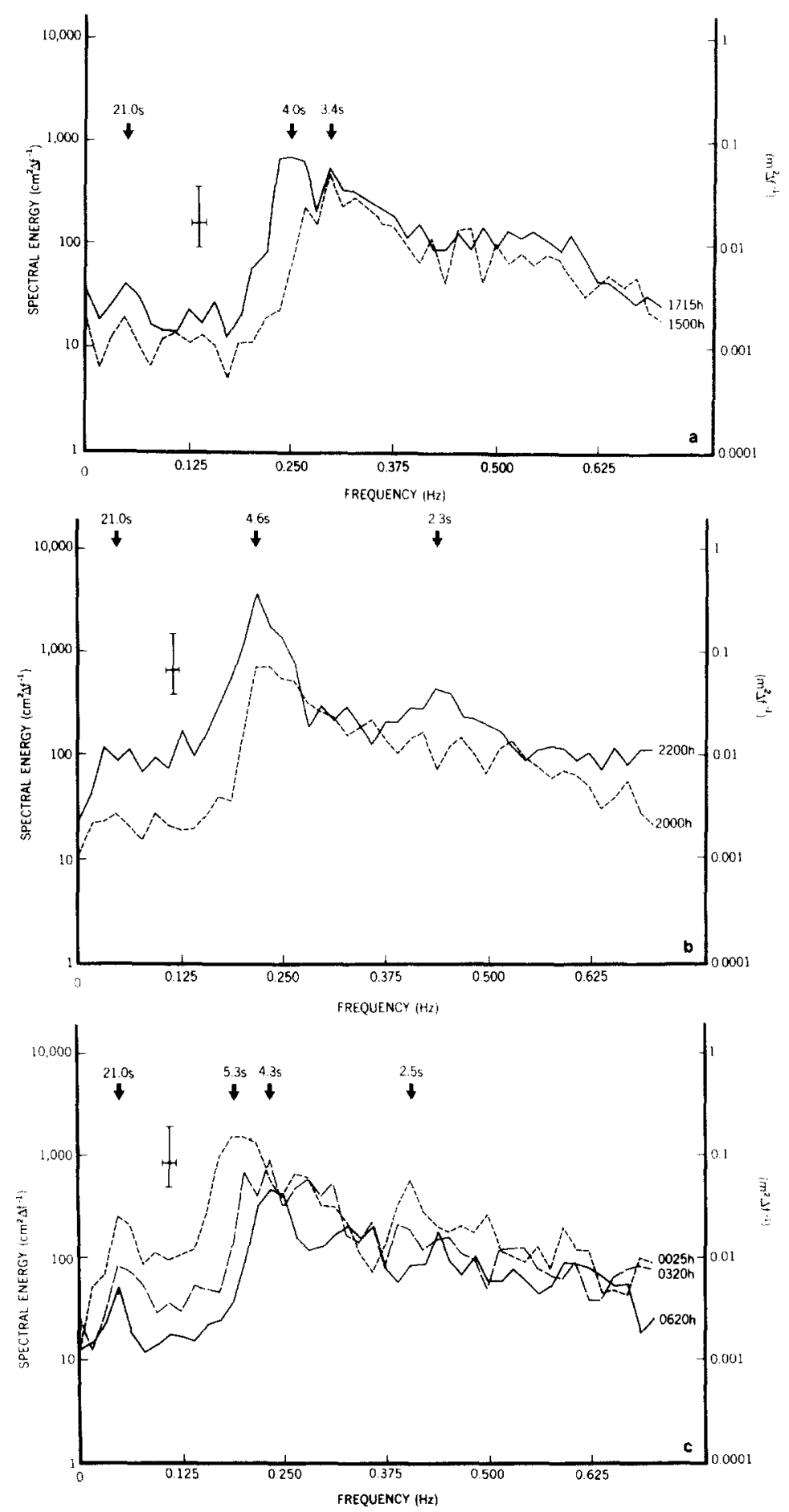

Fig.5. Wave spectra from the inner part of the surf zone through the early part of the storm (a), the storm peak (b), and the period from storm peak to decay (c). 
than $10 \%$ to the total variance of the surface elevation even at its maximum (Table III). It appears of more importance in the velocity field: the maximum contribution of this low frequency band to the total energies of the onoffshore and alongshore motions was found to be 22 and $25 \%$, respectively. Although energy at the incident frequency dominated the on-shore motions, the low frequency component was of equal importance in alongshore oscillations (Table III). Conclusive identification of the mode of this oscillation is not possible with the present dataset. Nevertheless, there does appear to be a spatial pattern to the energy at this frequency. Figure 6 documents the shorenormal variability in the spectra from a number of wave staffs and Fig.7 illustrates the spatial distribution of peak energies at both incident period and the longer period component $(0.047 \mathrm{~Hz})$ for on-offshore $(u)$ and alongshore $(v)$ velocity spectra. While there is a general tendency for energy at $0.047 \mathrm{~Hz}$ to decrease with distance from the shoreline (Fig. 7 and Table II) it is important to note that a strong peak in $u$ occurs over the crest of bar 2 in coincidence with a trough in the values of $v$. This suggests the trapping of energy near the shore as might be expected if the $21 \mathrm{~s}$ oscillation were an edge wave, and also the presence of a nodal point at the bar 2 location if the edge wave was in a standing mode. Evaluation of phase relationships between surface elevation $(n)$ and the two components of the horizontal velocity field ( $u$ and $v$ ), for the incident and low-frequency spectral peaks at positions close to the shoreline, support the presence of edge wave motions at $0.047 \mathrm{~Hz}$ (Table IV). In no case however, did this low-frequency component dominate the spectrum. In all cases incident wave energy was more important and only in two cases were the low-frequency peaks in the velocity spectra statistically significant (Fig.8).

TABLE III

Surf zone spectral energies, Wendake Beach, 1980:06:00:25

\begin{tabular}{|c|c|c|c|c|c|c|c|c|c|}
\hline \multirow{3}{*}{$\begin{array}{l}\text { Location offshore } \\
\text { (m) }\end{array}$} & \multicolumn{3}{|c|}{ Total energy $\left(\times 10^{3}\right)$} & \multicolumn{6}{|c|}{ Percentage of total* } \\
\hline & \multirow{2}{*}{$\begin{array}{l}\eta \\
\left(\mathrm{cm}^{2}\right)\end{array}$} & \multirow{2}{*}{$\begin{array}{l}u \\
\left(\mathrm{~cm}^{2} \mathrm{~s}^{-2}\right)\end{array}$} & \multirow{2}{*}{$\begin{array}{l}v \\
\left(\mathrm{~cm}^{2} \mathrm{~s}^{-2}\right)\end{array}$} & \multicolumn{2}{|l|}{$\eta$} & \multicolumn{2}{|l|}{$u$} & \multicolumn{2}{|l|}{$v$} \\
\hline & & & & $\overrightarrow{21 s}$ & $5 s$ & $21 \mathrm{~s}$ & $5 \mathrm{~s}$ & $21 \mathrm{~s}$ & $5 \mathrm{~s}$ \\
\hline $14(\mathrm{Tl})^{* *}$ & - & 15.0 & 31.2 & - & - & & & & \\
\hline 38 (T2) & 4.9 & 41.1 & 13.6 & 8 & 41 & 15 & 48 & 24 & 10 \\
\hline 57 (B2) & 26.9 & 44.0 & 23.1 & 10 & 47 & 22 & 43 & 23 & 24 \\
\hline 64 (B2) & 15.0 & 61.4 & 24.8 & 6 & 46 & 14 & 57 & 25 & 18 \\
\hline $94(\mathrm{~T} 3)$ & 8.0 & 33.8 & 6.5 & 4 & 43 & 9 & 53 & 23 & 27 \\
\hline 106 (B3) & 4.3 & 3.8 & 10.1 & 3 & 43 & 7 & 54 & 22 & 36 \\
\hline $118(\mathrm{~B} 3)$ & - & 59.1 & 7.8 & - & - & 3 & 53 & 20 & 11 \\
\hline $136(\mathrm{~B} 3)$ & 20.6 & - & - & 9 & 45 & - & - & - & - \\
\hline
\end{tabular}

*Values determined using the variance in unit bandwidth at these peak frequencies.

**T1, T2, T3 refer to the trough locations, and B2, B3 to the bar locations. 

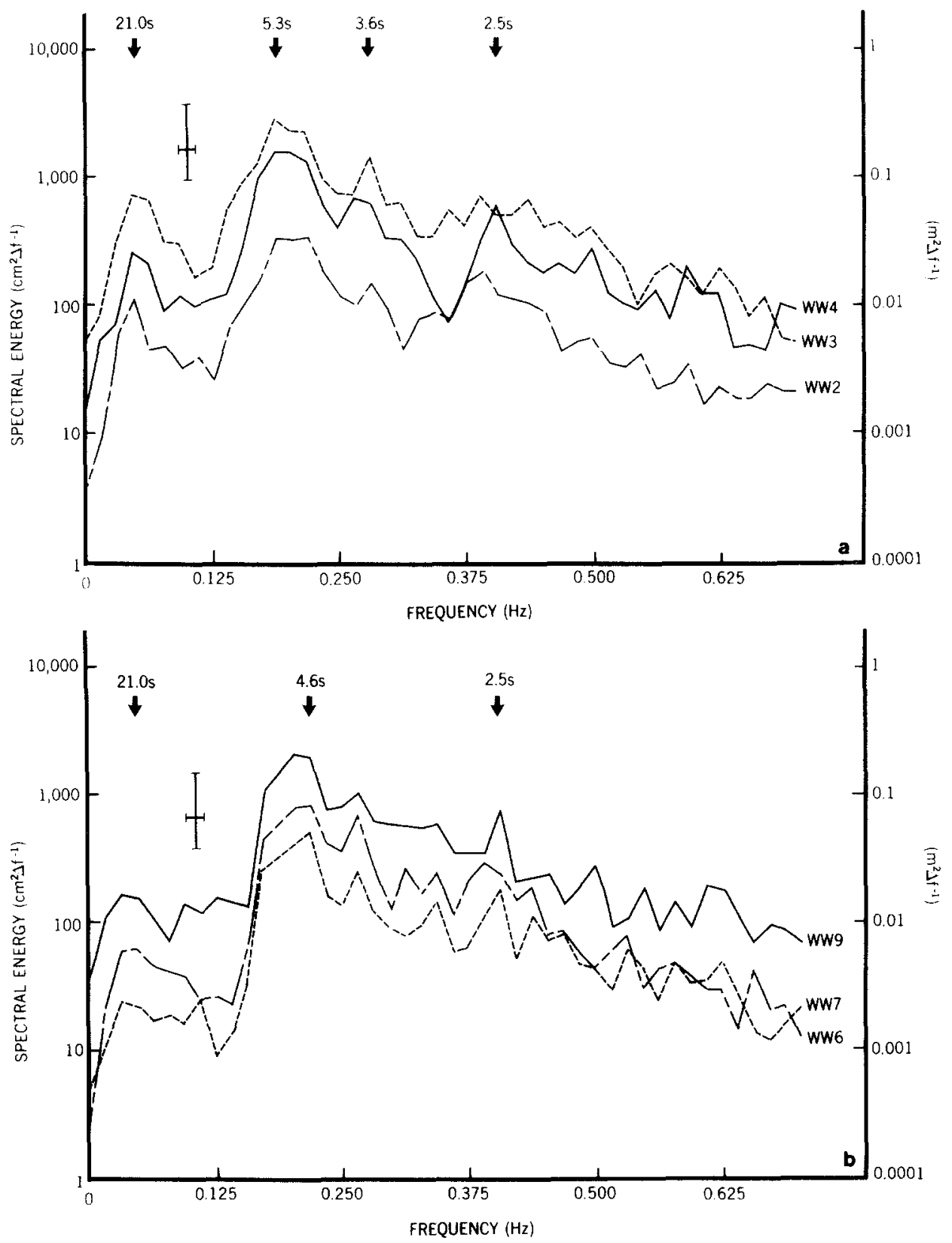

Fig.6. Wave spectra across the surf zone at the storm peak $(0025 \mathrm{~h})$. Note the strength of the low frequency oscillation at $21 \mathrm{~s}$ in the inner surf zone (a) compared to further offshore (b). Wave wire numbers refer to the locations in Fig. 2. 


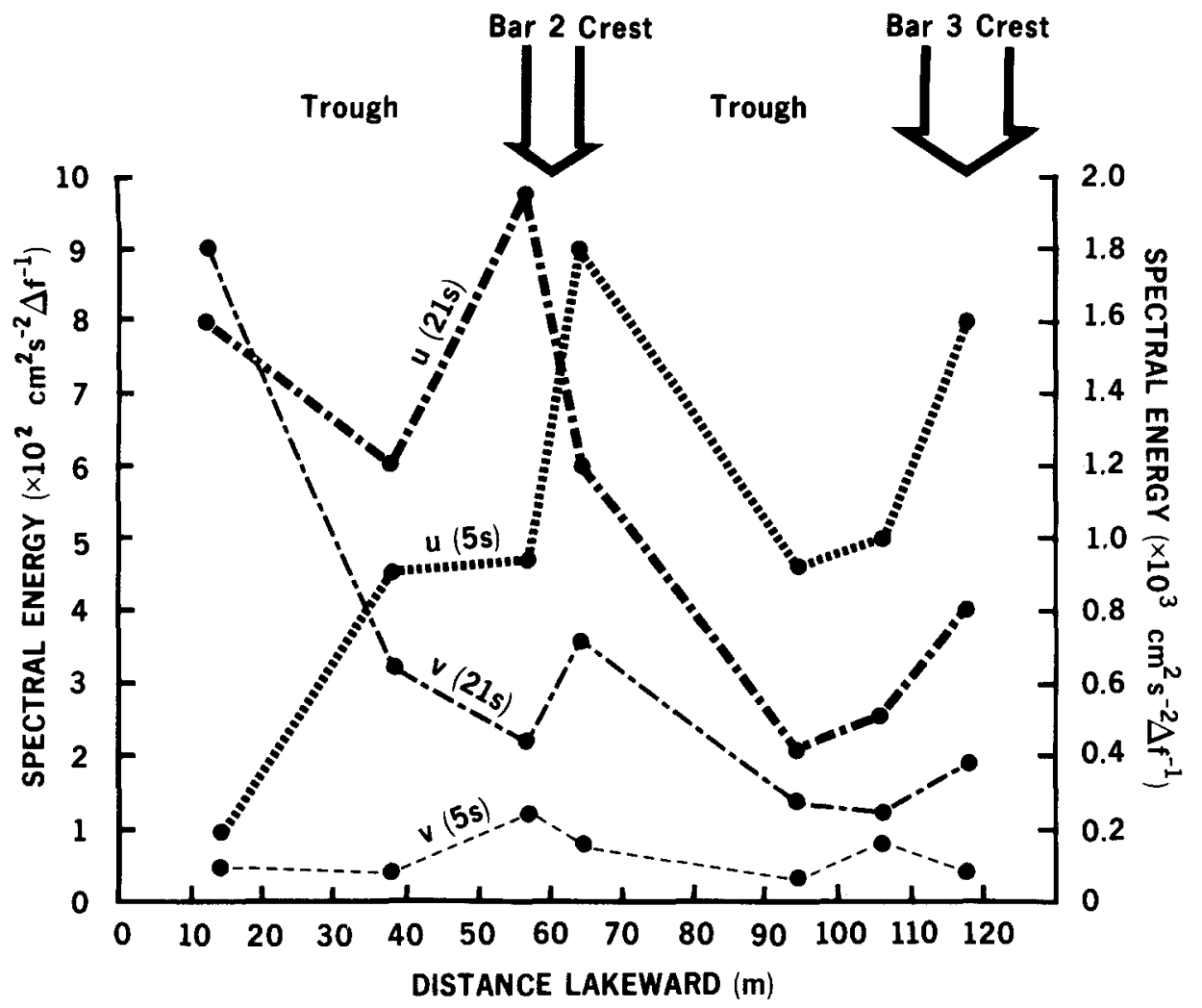

Fig.7. Spatial distribution of spectral energies for the incident peak, $5 \mathrm{~s}(0.188 \mathrm{~Hz})$ and the low-frequency peak, $21 \mathrm{~s}(0.047 \mathrm{~Hz})$ in the shore-normal $(u)$ and shore-parallel $(v)$ velocity spectra. For simplicity the value of the spectral density over one unit bandwidth at the peak is shown. Right-hand scale refers to the low-frequency peak.

\section{TABLE IV}

Phase relationships between surface elevation $(\eta)$, onshore velocity $(u)$ and longshore velocity $(v)$, Wendake Beach, 1980:06:00:25 and 06:25

\begin{tabular}{|c|c|c|c|c|}
\hline \multirow{2}{*}{$\begin{array}{l}\text { Time } \\
\text { (h) }\end{array}$} & \multirow{2}{*}{$\begin{array}{l}\text { Location offshore } \\
\text { (m) }\end{array}$} & \multirow{2}{*}{$\begin{array}{l}\text { Frequency } \\
(\mathrm{Hz})\end{array}$} & \multicolumn{2}{|c|}{ Phase (coherence) in degrees } \\
\hline & & & $\eta$ vs. $u$ & $u$ vs. $v$ \\
\hline \multirow[b]{2}{*}{0025} & 14 & $\begin{array}{l}0.047 \\
0.188\end{array}$ & $\begin{array}{r}+80(0.50) \\
-140(0.60)\end{array}$ & $\begin{array}{l}+14(0.47) \\
-15(0.75)\end{array}$ \\
\hline & 38 & $\begin{array}{l}0.047 \\
0.188\end{array}$ & $\begin{array}{l}+120(0.78) \\
-178(0.98)\end{array}$ & $\begin{array}{r}157(0.30) \\
+94(0.58)\end{array}$ \\
\hline \multirow[b]{2}{*}{0620} & 14 & $\begin{array}{l}0.047 \\
0.250\end{array}$ & $\begin{array}{r}+88(0.36) \\
-130(0.75)\end{array}$ & $\begin{array}{r}+3(0.32) \\
0(0.18)\end{array}$ \\
\hline & 38 & $\begin{array}{l}0.047 \\
0.250\end{array}$ & $\begin{array}{r}+60(0.30) \\
-165(0.98)\end{array}$ & $\begin{array}{r}-180(0.12) \\
-20(0.08)\end{array}$ \\
\hline
\end{tabular}



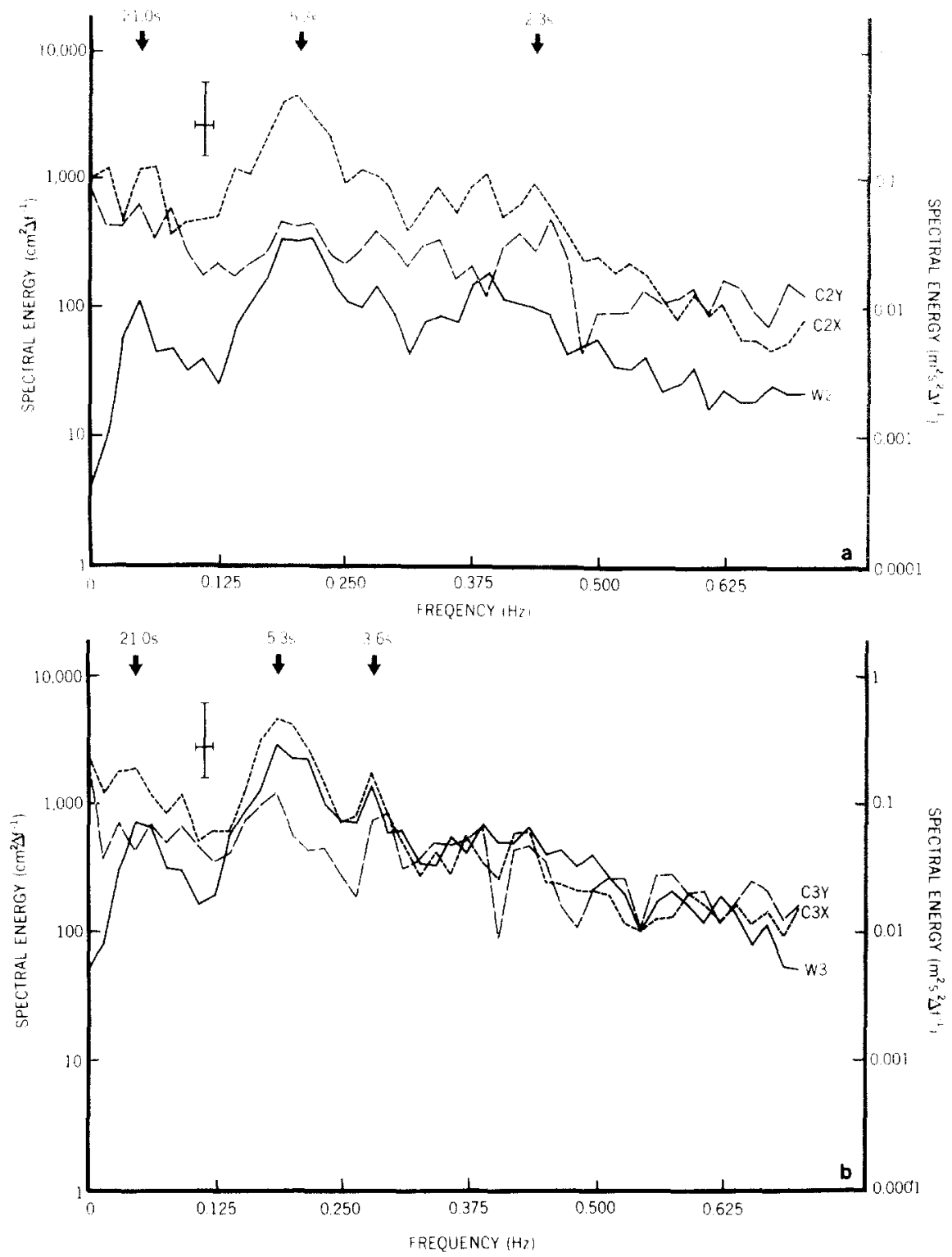

Fig. 8. Wave and current spectra at the storm peak $(0025 \mathrm{~h}$ ): (a) $38 \mathrm{~m}$ offshore; (b) $57 \mathrm{~m}$ offshore. $\mathrm{C} 2$ and $\mathrm{C} 3$ are current meter designations and X refers to the shore-normal and $\mathrm{Y}$ to the shore-parallel directions. $\mathrm{W} 2$ and $\mathrm{W} 3$ are wave wire designations. Locations are shown in Fig.2. 
Early in the storm ( 1500 and $1715 \mathrm{~h}$ ), wave orbital velocities were already sufficient to initiate sediment motion (Fig.9). Taking a conservative velocity of $0.2 \mathrm{~m} \mathrm{~s}^{-1}$ for the threshold of entrainment, it is evident that the Wendake Beach sands would be in motion across the whole of the three-bar system. Maximum instantaneous currents at these times were in excess of 0.7 and $1.3 \mathrm{~m} \mathrm{~s}^{-1}$, respectively. The mean flows (Fig.10) were offshore, but did not exceed $0.05 \mathrm{~m} \mathrm{~s}^{-1}$ and were therefore close to the instrument accuracy. At
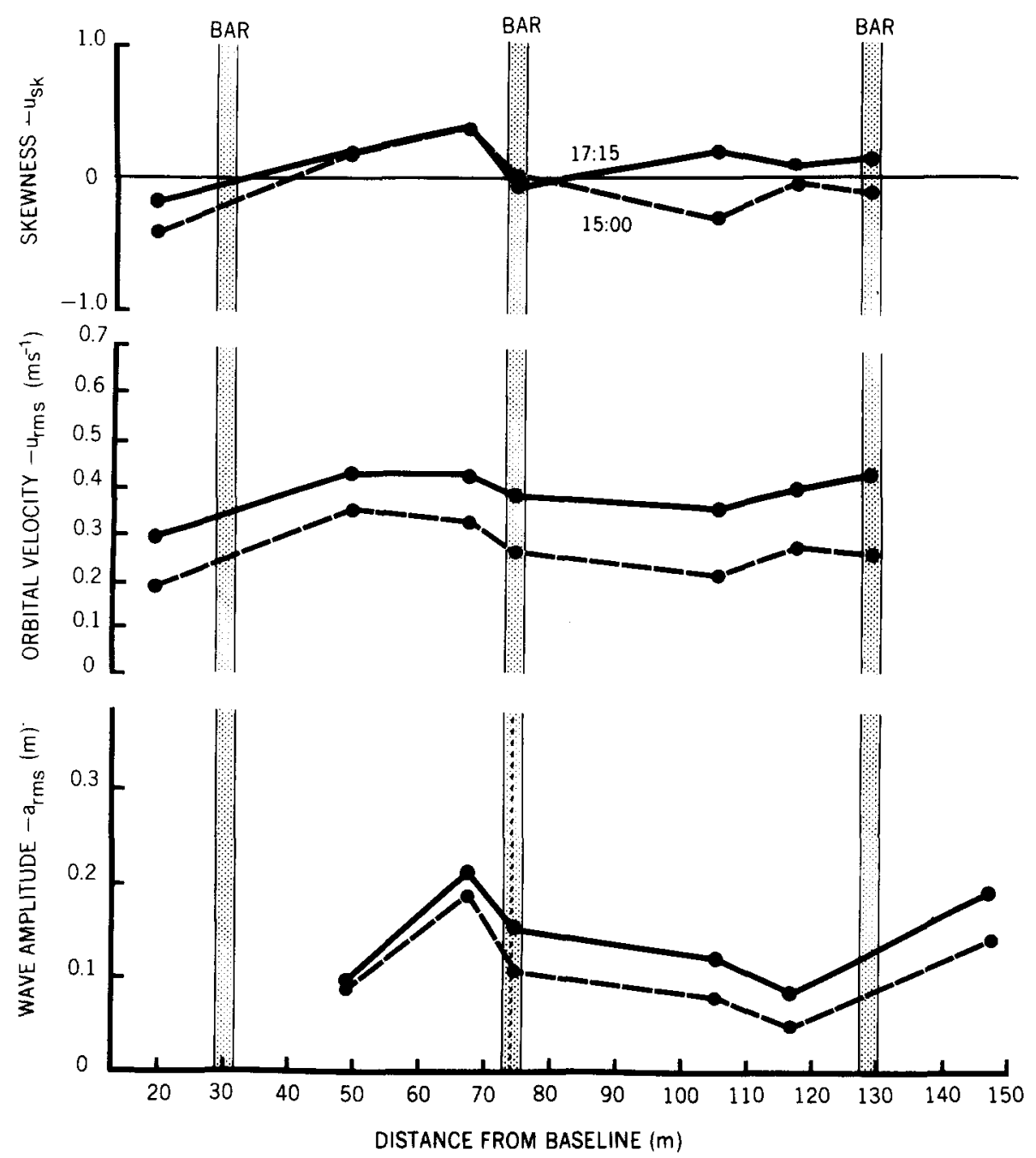

Fig.9. Spatial variability of wave amplitude, orbital velocity and orbital asymmetry across the surf zone, Wendake Beach, 1980:05:31:15:00 and 1980:05:31:17:15. Negative skewness is offshore. Dots mark bar crest locations and the vertical dashed line indicates the first breaker line based upon the depth-controlled breaking criterion. 


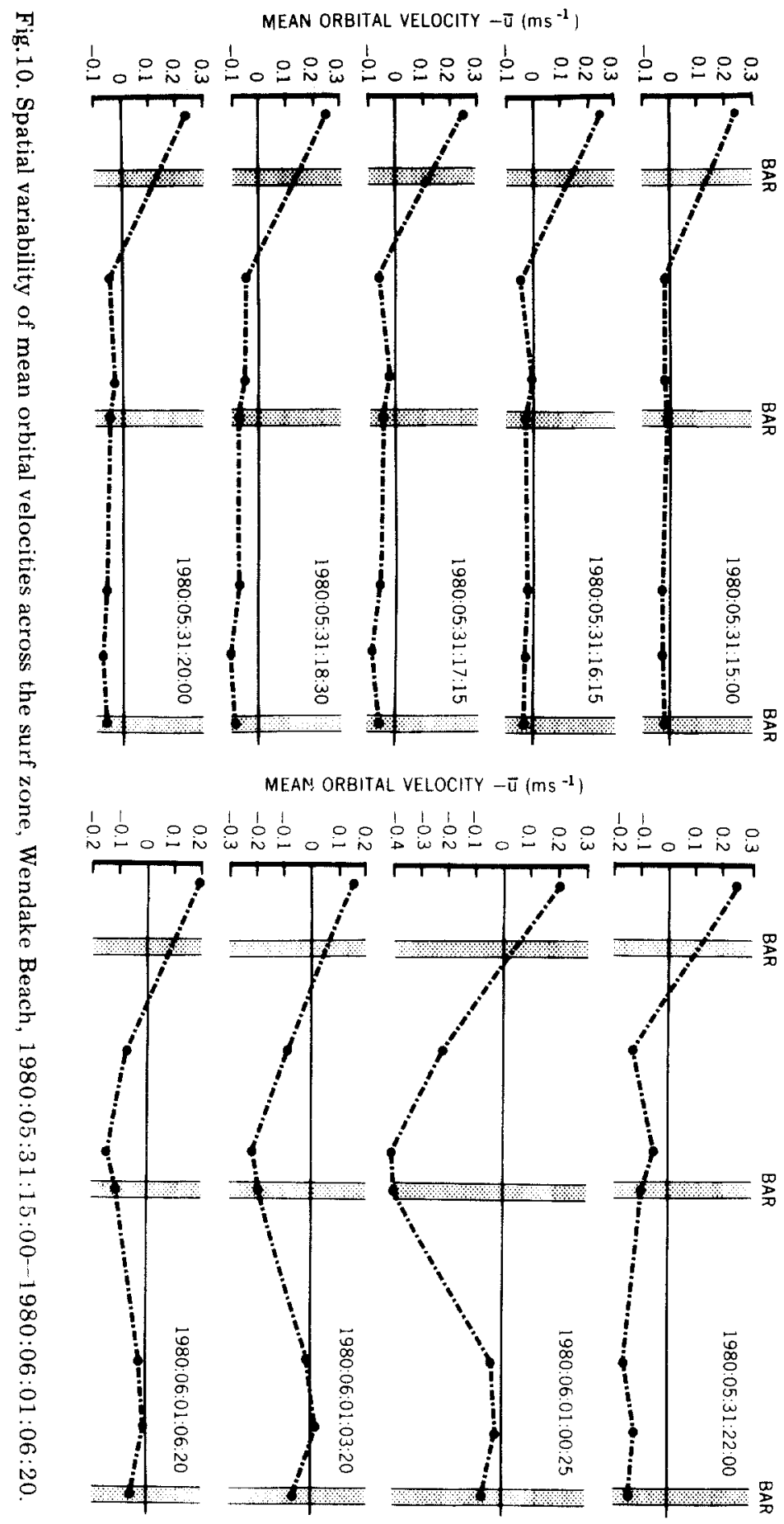


$1500 \mathrm{~h}$ wave breaking was initiated on the second bar and by $1715 \mathrm{~h}$ the surf zone width had expanded lakeward of the third bar (Fig.9). Relatively small variation in orbital velocity was measured across the surf zone, but strong orbital asymmetries were present in the troughs. Near symmetrical motion occurred on the bar crests. The basic pattern was one of lakeward asymmetry (negative skewness) in the innermost trough and landward asymmetry (positive skewness) in the second trough; an initial lakeward asymmetry changing to a landward asymmetry was evident in the outer trough (Fig.9).

As wave height increased during the storm so did the orbital velocities: at the storm peak $(2200-0025 \mathrm{~h}) u_{\mathrm{rms}}$ reached maxima in excess of $0.60 \mathrm{~m} \mathrm{~s}^{-1}$ (Fig.11), with peak orbital flows of $1.7 \mathrm{~m} \mathrm{~s}^{-1}$. As expected, maximum currents were found in the shallow water over the bar crests. However, since height loss through breaking was now occurring well-lakeward of the outer bar and across the full surf zone width, the largest velocities were on the outer bar with decreasing values landward (Fig.11).

After $2200 \mathrm{~h}$ a strong, steady lakeward drift was superimposed on the orbital velocities across virtually the whole of the surf zone. This drift reached values of $0.4 \mathrm{~m} \mathrm{~s}^{-1}$ in the second trough and across the crest of the second bar at $0025 \mathrm{~h}$ (Fig.10). Only in the very shallow zone landward of the first bar were mean flows landward (Fig.10), as an apparent response to bore development near the beach face. At $2200 \mathrm{~h}$ asymmetry in the oscillatory motion was landward across the whole of the surf zone (Fig.12), and could be capable of producing net transport opposed to that of the mean drift. Thus sediment transport differentials could be controlled by this asymmetry superimposed on the steady drift.

During the peak of the storm $(0025 \mathrm{~h})$, a pattern of mean flow and flow asymmetry developed which remained for the duration of wave activity (Figs.11 and 13). It was still present at $0620 \mathrm{~h}$ when wave heights and absolute orbital velocities had dropped to values almost identical to those at the beginning of the storm (cf. Figs.9 and 11).

On-offshore sediment transport, net sediment flux and morphological change will depend upon the interactions of mean flows with the flow asymmetries, provided flows are great enough to initiate transport. If, therefore, one can assume that most sediment transport and morphological change will be associated with the highest orbital velocities when bedload transport would be the highest (the storm peak), and with the decaying limb of the storm as any suspension settling accelerates, then the period $0025-0620 \mathrm{~h}$ becomes critical in any explanation of sediment flux.

The primary flow characteristics at this time were (Figs.10 and 13):

(a) Mean flows were offshore every where except landward of the first bar.

(b) Mean flows reached maxima on the landward slope and across the bar crest of the second bar $\left(0.4 \mathrm{~m} \mathrm{~s}^{-1}\right)$, decreasing both landward into the trough and lakeward across the outer trough and bar crest. In the outer part of the surf zone, flows were less than $0.1 \mathrm{~m} \mathrm{~s}^{-1}$.

(c) Flow asymmetries were onshore (positive $u_{\mathrm{sk}}$ ) landward of the central part of the second trough and lakeward of the centre of the outer trough. 

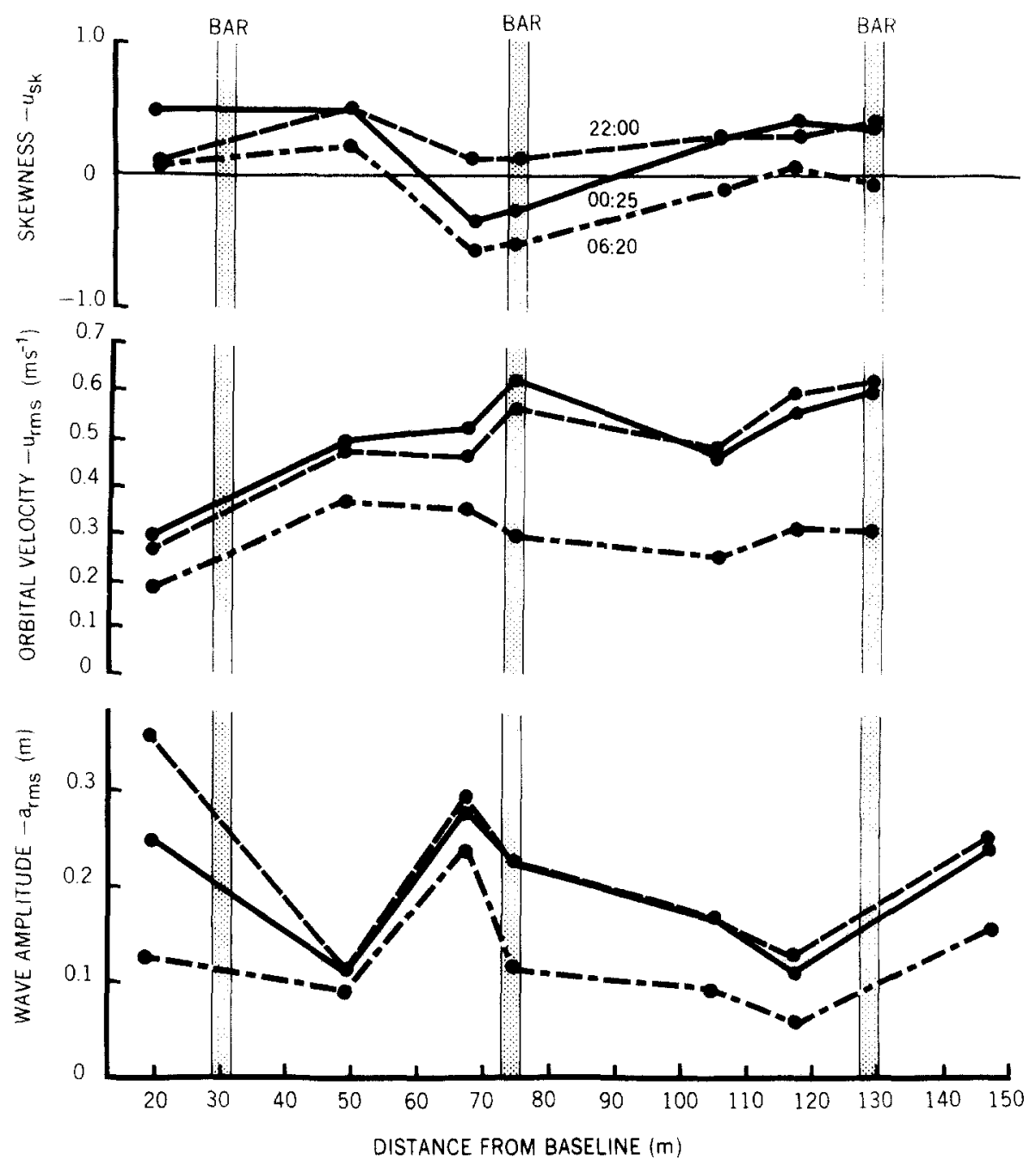

Fig.11. Spatial variability of wave amplitude, orbital velocity and orbital asymmetry across the surf zone, Wendake Beach, 1980:05:31:22:00, 1980:06:01:00:25 and 1980: $06: 01: 06: 20$.

Across the landward slope and crest of bar two, however, flow asymmetries were offshore with largest negative skewness values occurring in the part of the trough immediately landward of the bar slope and crest.

(d) Symmetrical flow fields must therefore have occurred in the second and outer troughs.

With respect to the contribution of secondary oscillations to the fluid motion described above it has already been noted that a very large difference exists between the spectral densities of the water surface elevation at the incident frequency and the low-frequency peak at $21 \mathrm{~s}$; this difference is not as great with respect to the two components of the velocity field especially 
WENDAKE BEACH SURF ZONE
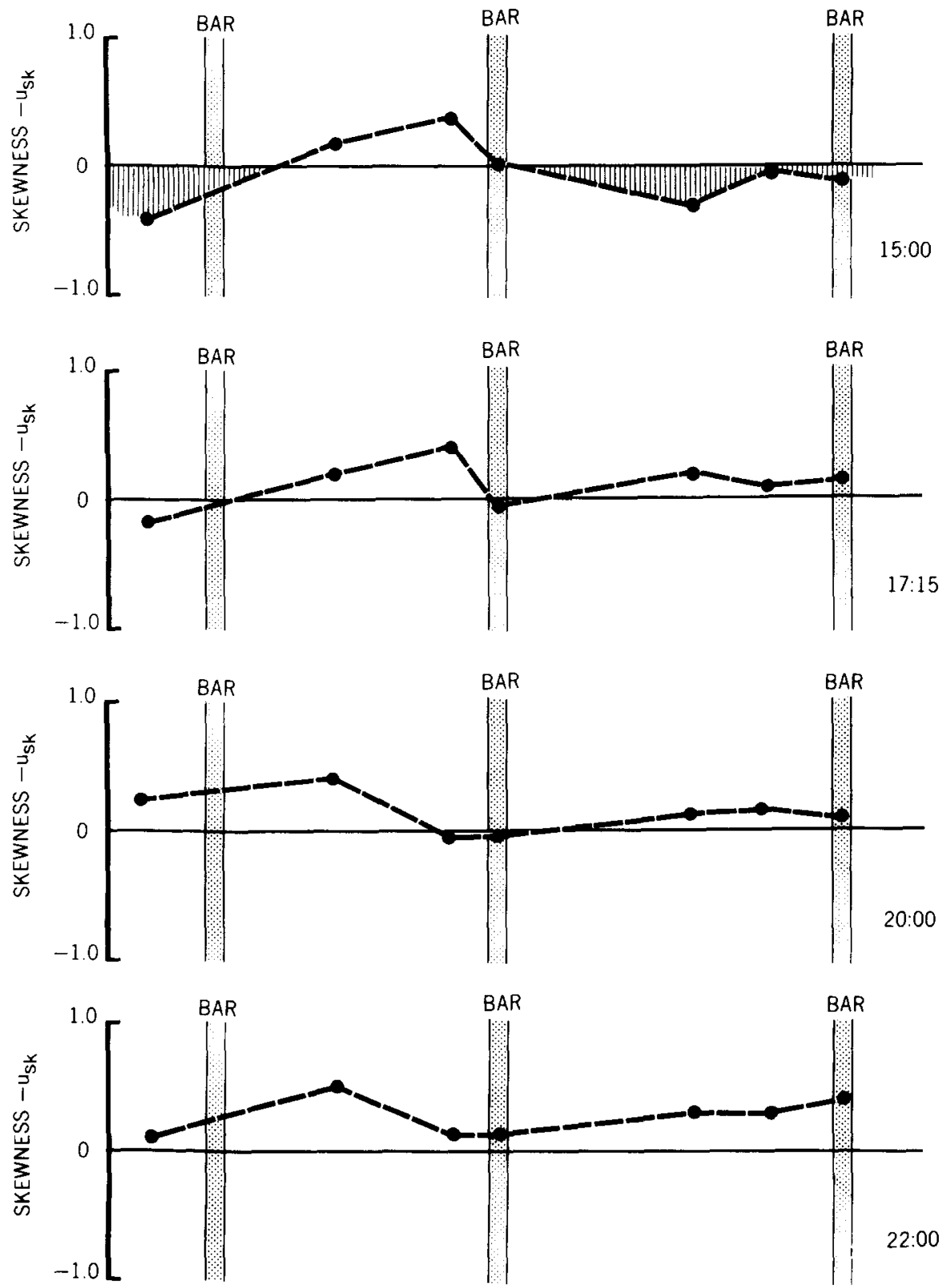

Fig.12. Spatial variability of orbital asymmetry across the surf zone, Wendake Beach, 1980:05:31:15:00-22:00. 


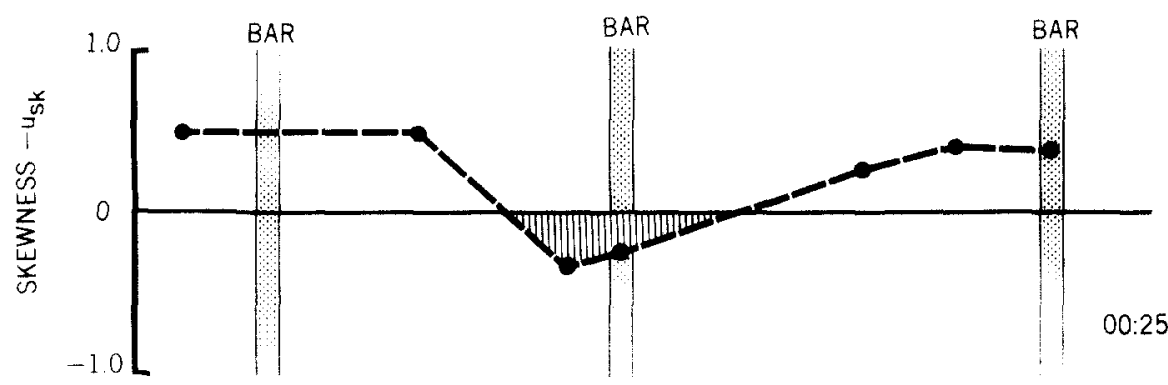

$00: 25$
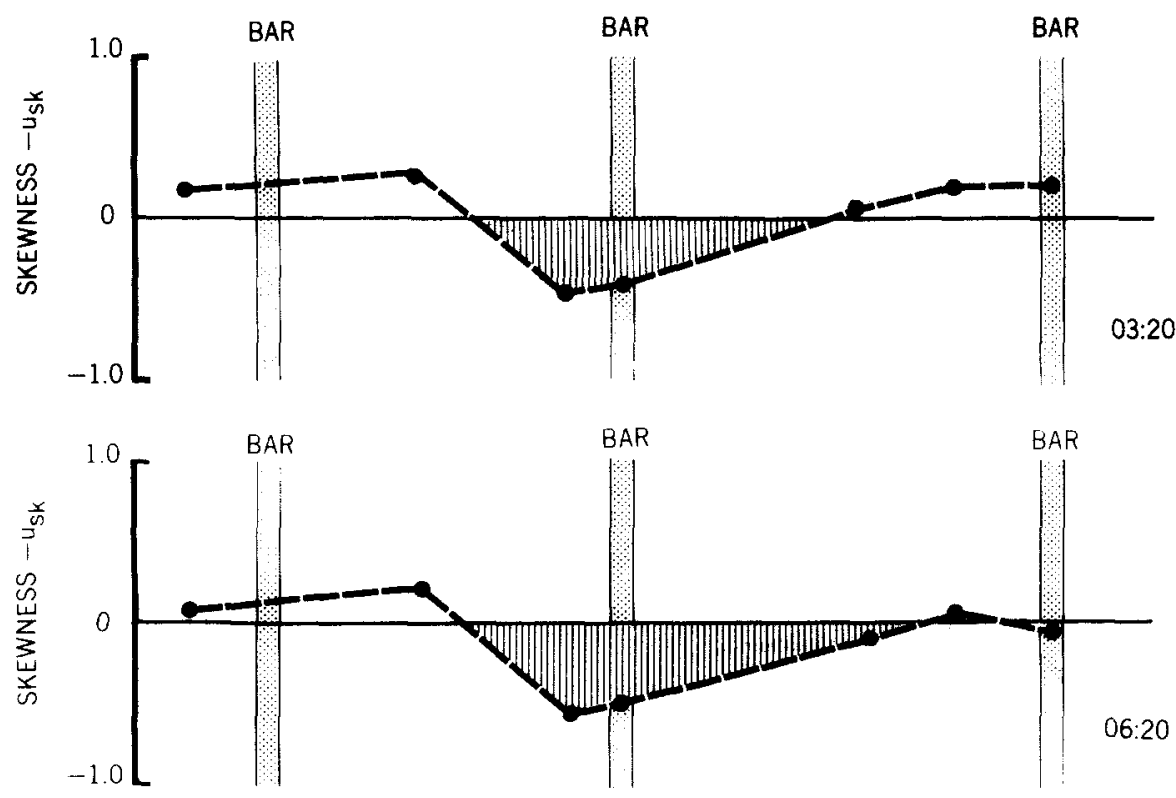

Fig.13. Spatial variability of orbital asymmetry across the surf zone, Wendake Beach, 1980:06:01:00:25-06:20.

close to the shoreline (Fig.8). However, the low-frequency peaks in the velocity structure are poorly defined and overall the surf zone is dominated by oscillatory currents at the incident wave frequency. Table II shows the relative contribution to nearshore currents of energy at the peak incident frequency and at $0.047 \mathrm{~Hz}$ during the time of maximum total energy and most significant low frequency spectral peak. Except very close to the shoreline, velocities associated with the incident waves are higher by a factor of 1.5 to 3 . If the total energies in the two peaks were considered this difference would be greater still. Contrary to the results of similar studies, the currents at Wendake Beach are dominated by oscillations at the incident frequency. 
Spatial and temporal variability of shore-parallel currents

During the early part of the storm (Fig.14) the time-averaged longshore component of motion in the surf zone was somewhat non-coherent, generally less than $0.20 \mathrm{~m} \mathrm{~s}^{-1}$ and thus close to or below the threshold of sediment motion. However, these flows were superimposed on the shore-normal oscillations, which would have set sediment in motion at this time and thus longshore advection of sediment could occur.

By $1830 \mathrm{~h}$ a strongly coherent flow pattern was established and maintained until the peak of the storm. Maximum velocities occurred on the lower lakeward slopes of the bars and reached a value in excess of $0.40 \mathrm{~m} \mathrm{~s}^{-1}$ in the

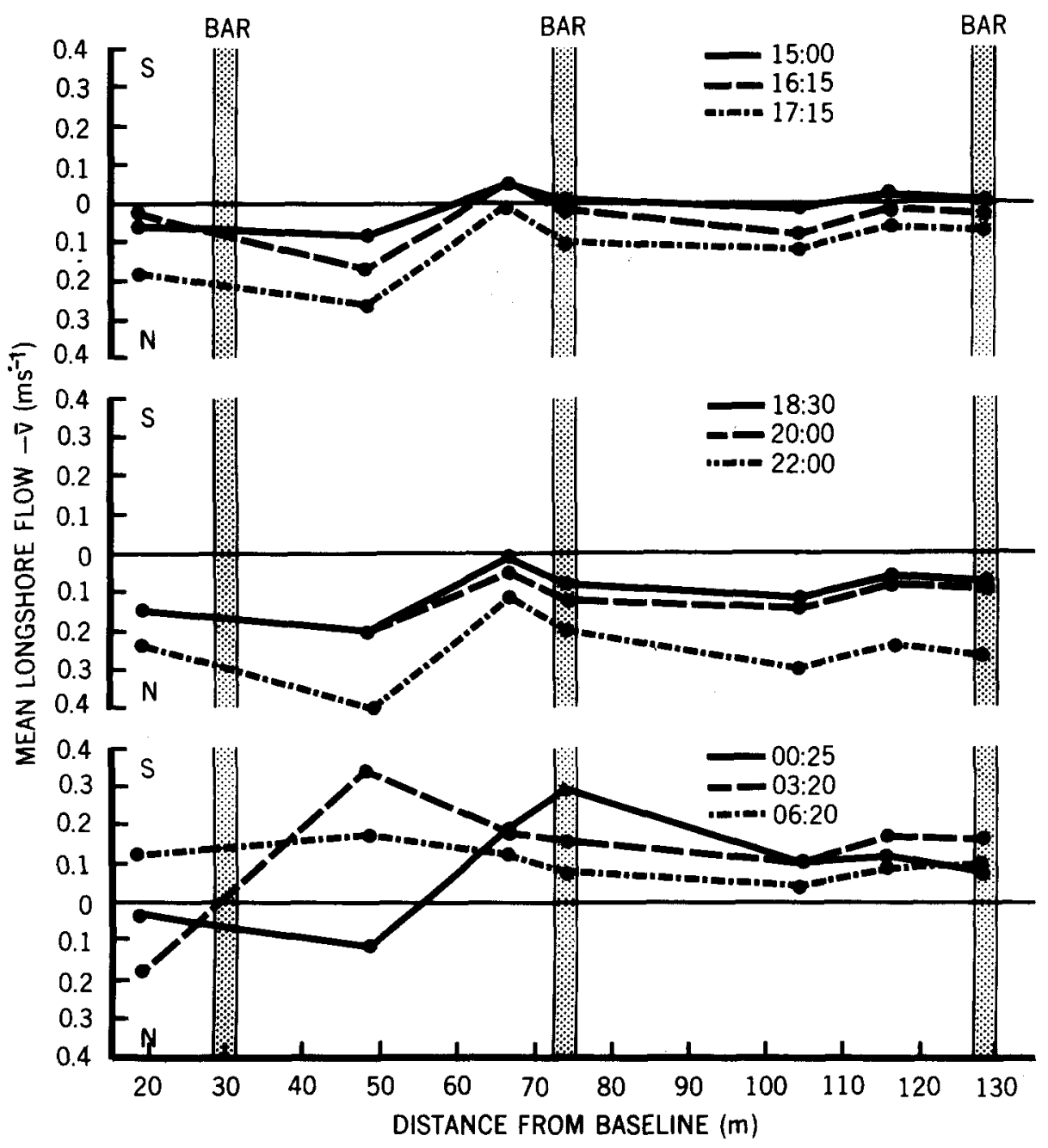

Fig.14. Spatial variability of shore-parallel currents across the surf zone, Wendake Beach, 1980:05:31:15:00-06:20. 
second trough at $2200 \mathrm{~h}$. Minima occurred just lakeward of the bar crests in both second and third trough-bar systems. Between 2200 and $0025 \mathrm{~h}$ a change in the direction of wind and wave approach caused a bi-directional, disequilibrium response in the longshore current (Fig.14). It will be recalled, however, that a strongly coherent pattern of shore-normal flows existed at this time. Upon reversal of the longshore current, maximum flows occurred in the second trough and the lowest velocities were now occurring in the outer trough. As waves decayed so did the shore-parallel flows until velocities across the surf zone were again less than $0.20 \mathrm{~m} \mathrm{~s}^{-1}$ by $0620 \mathrm{~h}$, although the orbital velocities $\left(u_{\text {rms }}\right)$ were still well above this value.

\section{Sediment flux and morphological response}

From the preceding discussion it is apparent that the potential for significant sediment motion was present over most of the nearshore zone throughout the storm and that net transport in the on-offshore direction could have been forced by both the mean flow and asymmetries associated with the orbital motions. Furthermore, spatial gradients in these flows (giving rise to net water and sediment flux) and local slopes (controlling the gravity potential on transported sediment) would interact to determine whether erosion (accelerating transport rates), deposition (decelerating transport rates) or no change (constant transport rates) would occur. Shore-parallel flows would become increasingly important where orbital velocities were low, nearsymmetrical, or both. Any shore-normal gradient in these longshore currents could then produce transport differentials leading to shore-normal patterns in sediment erosion and accretion.

Examination of pre- and post-storm profiles along the instrument transect and at $30 \mathrm{~m}$ either side revealed bars present at both times, and with relatively small differences in morphology. Thus the bars are not totally destroyed by a single episode of storm-waves, but rather are in some form of equilibrium, either with a single storm or a series of storm events. Recent analysis of depth of activity and bed elevation data using a grid of 51 rods for a series of six storms at this location suggest strongly the existence of a steady state, at least in the overall sediment budget (Greenwood, in prep.).

In this storm, morphological changes were evident both from profile data and the depth-of-activity rods. In general there was a landward shift of the first and second bar crests ( 5 and $10 \mathrm{~m}$, respectively), while the outer bar crest remained stable. Accretion of both second and third bars occurred, with erosion of the adjacent troughs. Landward movement of bars 1 and 2 was associated with a southerly alongshore shift in the sinuous form of the two bars. The latter is important, since southward flowing currents only occurred at the storm peak and during the decay period, after the major switch in the direction of wave approach at approximately $0000 \mathrm{~h}$.

Figure 15 illustrates the local depths of activity and bed elevation change across the bar system together with the spatial distribution of the primary hydrodynamic parameters at the peak of the storm $(0025 \mathrm{~h})$. This particular 
data set was used because: (1) at this time both orbital velocities and asymmetries were greatest and thus likely to reflect the most important sediment transport phase of the storm; and (2) this general pattern was consistently present for the longest part of the storm (at least six hours).

Sediment reactivation was, as expected, controlled strongly by the antecedent morphology: in the shallow water over the bar crests, where orbital velocities were greatest, depth of activity reached a maximum. In contrast, the outer trough and lakeward slopes of the third bar with deeper water, lower wave heights and lower orbital velocities were marked by minima. In the trough landward of bar 2 a relatively high value for sediment reactivation was obtained because of the shallowness of the water.

It is rather surprising, however, given the measured currents, that the depth of activity relative to the pre-storm surface was not larger. Maxima were only $14 \mathrm{~cm}$ on both second and third bars. This indicates that with high, relatively uniform, bed stress, sediment entrainment reaches a maximum, which cannot be increased regardless of the duration of applied stress unless considerable net transport of sediment occurs. The latter was clearly not the case: although considerable volumes of sediment were set in motion during the storm (the average depth of activity was $9 \mathrm{~cm}$ ), the net flux was less than two percent of the nearshore control volume (Greenwood, in prep.).

Bed elevation change indicated accretion of the bars and scouring of the troughs, and thus bar growth during storms: however, these changes were small, reaching maxima of only a few centimeters (Fig.15). This would suggest that conditions of near-equilibrium transport existed over the locally varying nearshore slopes for much of the storm. This could have been achieved through a continuous, but uniform, sediment transport rate over the bar system or, more probably, by some form of oscillating equilibrium, where a balance existed between the net oscillatory flows (mean and asymmetry), the local slope and sediment inertia.

Accretion on the landward slope and crest of bar 2 combined with erosion of the adjacent trough would account for the observed landward migration of the bar crest (Fig.15). This is best explained by increasing landward flows from the centre of this trough landward, and a similar increase in lakeward flows from the centre of the trough lakeward (Fig.15). Such a pattern was evident in both the mean flow $(\bar{u})$ and flow asymmetry $\left(u_{\text {sk }}\right)$. The trough thus represents an erosional node. Decreases in both the mean flows lakeward and the lakeward asymmetries toward and across the landward slope and crest of bar 2 would explain the deposition here; the relative steep landward slope $\left(3-7^{\circ}\right)$ would provide further restraint on the lakeward transport. Enhancement of this pattern would be unlikely as a result of shore-parallel flows since the shore-parallel currents were lower in this second trough than on the landward slope and crest of the adjacent bar (see Fig.15).

Decreasing lakeward mean flows and flow asymmetries lakeward of the crest of the middle bar, would suggest continuing accretion into the centre of the outer trough (albeit somewhat less than on the landward side and crest of the bar). Also orbital asymmetries either side of the outer trough 

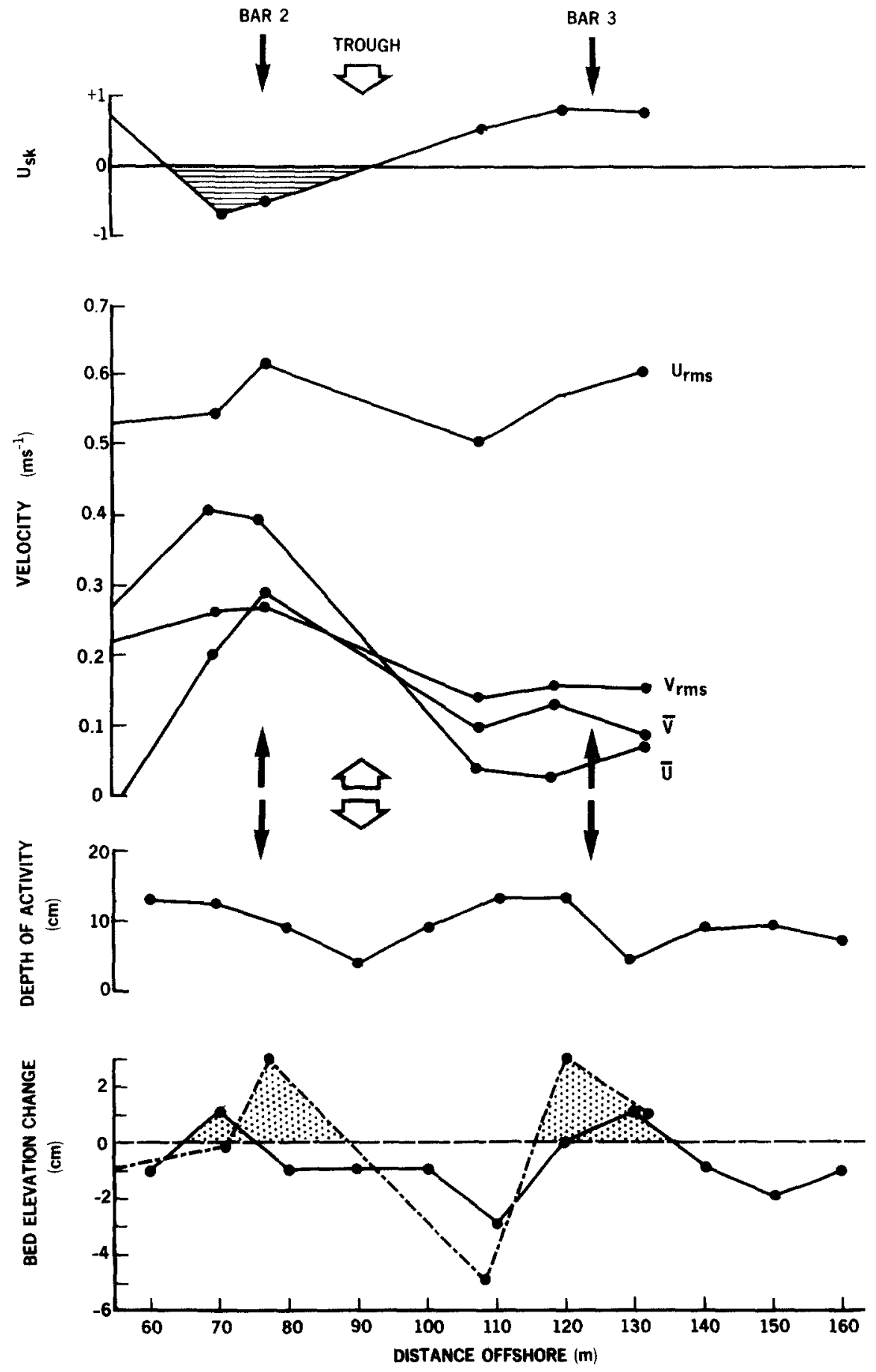
suggest convergence of sediment transport paths towards a depositional node in the centre of this outer trough. In fact erosion $(3-5 \mathrm{~cm})$ characterizes this location. It would appear, therefore, that with a reduction in $u_{\mathrm{rms}}, \bar{u}$ and $u_{\mathrm{sk}}$, and the consequent reduction in total load (corroborated in part by the depth of activity data), the longshore currents become the primary advecting agents (Fig.15) and caused the observed erosion.

Across the crest of the outer bar, bed elevation changes were positive on the landward side indicating accretion and negative on the lakeward side indicating erosion (Fig.15). At this location mean orbital flows were low, as indeed were mean longshore flows; it would seem that the best correlation is between the strong landward asymmetries in the orbital velocity field and a landward movement of sediment across the bar crest (Fig.15).

\section{DISCUSSION AND CONCLUSIONS}

Sediment transport and morphological change in the multiple bar system at Wendake Beach are most satisfactorily explained by the interrelationship of spatial gradients in the means and asymmetries of shore-normal oscillatory currents with the local slopes. Orbital asymmetries integrated over time represent a steady sediment transport potential which, together with the mean flows, is superimposed on the initial entrainment induced by the orbital motions themselves.

Figure 16 summarizes the patterns of fluid flow, erosion, deposition and morphological response that can be inferred from the field measurements. Sediments accumulate on the bars and are scoured from adjacent troughs during storms to cause bar growth: the alignment of scour and accretion relative to the pre-storm topography may cause a shift in bar location lakeward or landward. Sediment deposition occurs, paradoxically, in areas with the highest absolute orbital speeds: it results from spatial decreases in the orbital asymmetry and thus in the steady sediment drift. The gravitational resistance to sediment in transport is enhanced wherever local bed slopes oppose the steady drift and in some cases may aid accretion, as for example on the landward slope of bar 2 (Fig.16). Erosion results also form gradients in the orbital asymmetries, but in this case the asymmetries increase spatially and thus the sediment transport potential increases. Reversals (in the directional sense) of the orbital asymmetries can create either erosional nodes, as in the case of the middle trough, or depositional nodes, as in the case of outer trough (Fig.16).

Shore-parallel steady currents contribute to the net alongshore advection of sediment. They are of prime importance to the shore-normal patterns of

\footnotetext{
Fig.15. Spatial distribution of bed elevation change, depth of activity, orbital velocity $\left(u_{\mathrm{rms}}\right.$ and $\left.\bar{u}\right)$, orbital asymmetry $\left(u_{\mathrm{sk}}\right)$ and longshore current velocity ( $v_{\text {rms }}$ and $\bar{v}$ ) across the outer 2 bar-trough systems, at Wendake Beach. Hydrodynamic data are from the storm peak, 1980:06:01:00:25. $\bar{u}$ is offshore at all points and $\bar{v}$ is to the south at all points. With respect to bed elevation change and depth of activity, the solid line represents data from line IN and the dotted line, data from line 0.
} 


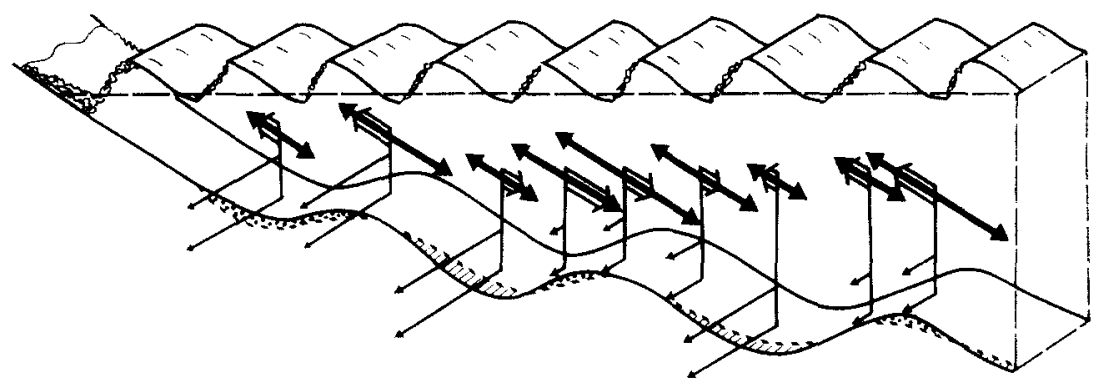

Fig.16. Generalized fluid flows, sediment flux and morphological response over the nearshore bars at Wendake Beach inferred from measurements 1980:05:31-1980:06:01. The relative magnitu de of near bed, shore-normal oscillatory flow is shown by the solid double arrow and the direction and magnitude of the net flows (resulting from mean flows and flow asymmetries) by the broad open arrow. The relative magnitude of the shore-parallel flow is shown by the pairs of thin arrows. Cross-hatching represents areas of erosion and dots areas of accretion. A solid line indicates the post-storm profile.

sedimentation where absolute orbital velocities are small and/or symmetrical. The relatively strong longshore current in the outer trough is the most likely cause of erosion here since the orbital asymmetries indicate a depositional node.

The energy driving both shore-normal and shore-parallel currents at Wendake Beach was primarily from incident, wind-generated waves. Secondary waves were present during the peak of the storm, but contributed relatively little energy to the total spectrum. Waves at the frequency of the first harmonic of the incident wave were associated with breaking, and a lowfrequency oscillation at a period four times that of the incident period was significant very close to the shoreline. The latter would appear to be a standing edge wave formed during the storm peak and remaining for the duration of the storm. The strong mean on-offshore flows and orbital asymmetries were coincident in time with the appearance of the edge wave and it is tempting to conclude a causal relationship as suggested by previous workers (e.g. Bowen and Inman, 1971; Holman and Bowen, 1982). If indeed the latter is correct then the edge wave node located over bar 2 would be consistent with Symonds and Huntley's (1980) observation of a resonant edge wave controlled by bar spacing. Furthermore, it would suggest that bars form under nodes of long waves (Carter et al., 1973) and thus result primarily from bedload transport rather than suspension load (Bowen, 1980). Evidence from primary sedimentary structures (Greenwood, in prep.) indicates a predominance of bedding produced by oscillation ripples, megaripples and sheet flow. No good example of massive bedding as might be produced by suspension fallout was ever observed. Secondary waves at a frequency of the first harmonic also coincided with the storm peak, in association with extensive wave breaking. If, as seems probable, such waves are dispersive (Thornton, 1979) then interactions with the primary wave may be capable of producing the orbital patterns observed. Certainly such wave-wave interactions have been 
proposed for bar genesis (e.g. Hulsbergen, 1974; Bijker et al., 1976; Van de Graaf and Tilmans, 1980; Boczar-Karakiewicz and Bona, 1982).

The present paper provides only a qualitative interpretation of the relationships between fluid and sediment motions, and their integration into a quantitative model remains for future work. At this time a plethora of theories exist for predicting shore-normal transport (some purely analytical others based on results from model experiments) and only detailed comparisons along the lines of those of Bowen (1980), Seymour and King (1982) and Bailard (1983) will determine the most appropriate predictor for sediment transport in a barred system such as Wendake Beach.

\section{ACKNOWLEDGEMENTS}

This study forms part of a continuing research programme in Nearshore Hydrodynamics and Sedimentation supported by equipment (E39218, E6614) and operating (A7956) grants awarded to B.G. from the Natural Sciences and Engineering Research Council of Canada. A University of Toronto Open Fellowship, an Ontario Graduate Scholarship and a Postdoctoral Scholarship at Woods Hole Oceanographic Institution assisted D.J.S. Computer costs were defrayed by both Scarborough College and the Department of Geography, University of Toronto. The Academic Workshops at Scarborough College provided instrument design and construction and the Graphics and Photography Department assisted with the illustrations. Invaluable field and laboratory assistance was provided by M. Rollingson, P. Christilaw and R. Sutherland (Scarborough College) and R.G.D. DavidsonArnott and D.C. Randall (University of Guelph). The writing of this paper was greatly assisted by the facilities and hospitality received by the senior author during research leave visits to the Universities of Uppsala, Sweden and Sydney, Australia. In particular Professor J.O. Norrman, Goran and Bodil Albjar (Uppsala), and Professor M. Daly and Dr. Andy Short (Sydney) are to be thanked. Drs. J. Bailard and A.H. Sallenger reviewed the manuscript and are thanked for their comments. The results and interpretations presented in this paper are, however, solely the responsibility of the authors.

\section{REFERENCES}

Bailard, J.A., 1981. An energetics total load sediment transport model for a plane sloping beach. J. Geophys. Res., 86: 10,938-10,954.

Bailard, J.A., 1983. Modeling offshore transport in the surf zone. Proc. 18th Coastal Engineering Conf., Cape Town, pp.1419-1438.

Bailard, J.A. and Inman, D.L., 1981. An energetics bedload model for a plane sloping beach: local transport. J. Geophys. Res., 86: 2035-2043.

Bijker, E.W., Van Hijum, E. and Vellinga, P., 1976. Sand transport by waves. Proc. 15th Coastal Engineering Conf., Honolulu, Hawaii, pp.1149-1167.

Boczar-Karakiewicz, B. and Bona, J.L., 1982. Shallow water waves over mildly varying topography. Abstracts, 18th International Conf. on Coastal Engineering, Cape Town, pp. 275-276. 
Bowen, A.J., 1980. Simple models of nearshore sedimentation; beach profiles and longshore bars. In: S.B. McCann (Editor), The Coastline of Canada. Geol. Surv. Can., Pap. 80-10, pp.1-11.

Bowen, A.J. and Inman, D.L., 1971. Edge waves and crescentic bars. I. Geophys. Res., $76 ; 8862-8871$.

Bowman, D. and Goldsmith, V., 1983. Bar morphology of dissipative beaches: an empirical model. Mar. Geol., 51: 15-33.

Carter, T.G., Liu, P.L.-F. and Mei, C.C., 1973. Mass transport by waves and offshore sand bedforms. J. Waterways, Harbors Coasts, Am. Soc. Civ. Eng., WW2: 165-184.

Davidson-Arnott, R.G.D. and Randall, D.C., 1984. Spatial and temporal variations in spectra of storm waves across a barred nearshore. In: B. Greenwood and R.A. Davis, Jr. (Editors), Hydrodynamics and Sedimentation in Wave-Dominated Coastal Environments. Mar. Geol., 60: 15-30 (this volume).

De Beaumont, E., 1845. Lecons de Géologique Practique. Paris.

Dixon, W.J., 1971. BMD: Biomedical Computer Programs. University of California Press, Berkeley, Calif., 600 pp.

Dixon, W.J. and Brown, M.B., 1979. BMD P-79: Biomedical Computer Programs, P-Series, University of California Press, Berkeley, Calif.

Galvin, C.J., 1972. Wave breaking in shallow water. In: R.F. Meyer (Editor), Waves on Beaches and Resulting Sediment Transport. Academic Press, New York, N.Y., pp.413-455.

Goldsmith, V., Bowman, D. and Kiley, K., 1982. Sequential stage development of crescentic bars: HaHoterim beach, southeastern Mediterranean. J. Sediment. Petrol, 52 : $233-249$.

Grant, W.P. and Madsen, O.S., 1979. Combined wave and current interaction with a rough bottom. J. Geophys. Res., 84: 1797-1808.

Greenwood, B., 1982. Bars. In: M.L. Schwartz (Editor), Encyclopaedia of Beaches and Coastal Environments. Dowden, Hutchinson and Ross, Stroudsberg, Pa., pp.135-139.

Greenwood, B., 1983. Hydrodynamics and sedimentation in barred nearshores: a review of work by the Scarborough Campus Coastal Research Group. In: N.A. Rukavina (Editor), Proc. Third Workshop on Great Lakes Coastal Erosion and Sedimentation. Natl. Water Research Institute, Burlington, Ont., pp.45-48.

Greenwood, B. and Davidson-Arnott, R.G.D., 1979. Sedimentation and equilibrium in wave-formed bars: a review and case study. Can. J. Earth Sci., 16: 312-332.

Greenwood, B. and Hale, P.B., 1980. Depth of activity, sediment flux and morphological change in a barred nearshore environment. In: S.B. McCann (Editor), The Coastline of Canada: Littoral Processes and Shore Morphology. Geol. Surv. Can., Pap. 80-10, pp.89-109.

Greenwood, B. and Mittler, P.R., 1984. Sediment flux and equilibrium slopes in a barred nearshore. In: B. Greenwood and R.A. Davis, Jr. (Editors), Hydrodynamics and Sedimentation in Wave-Dominated Coastal Environments. Mar. Geol., 60: 79-98 (this volume).

Greenwood, B. and Sherman, D.J., 1983. Shore-parallel flows in a barred nearshore. Proc. 18th Coastal Engineering Conf., Cape Town, pp.1677-1696.

Greenwood, B., Hale, P.B. and Mittler, P.R., 1980. Sediment flux determination in the nearshore zone: prototype measurements. In: Workshop on Instrumentation for Currents and Sediments in the Nearshore Zone, National Research Council of Canada, Associate Committee for Coastal Erosion and Sedimentation, Ottawa, Ont., pp.99-120.

Guza, R.T. and Inman, D.L., 1975. Edge waves and beach cusps. J. Geophys. Res., 80: $2997-3012$.

Holman, R.A., 1981. Infragravity energy in the surf zone. J. Geophys. Res., 86: 64426450.

Holman, R.A. and Bowen, A.J., 1982. Bars, bumps and holes: models for the generation of complex topography. J. Geophys. Res., 87: 457-468.

Holman, R.A., Huntley, D.A. and Bowen, A.J., 1978. Infragravity waves in storm conditions. Proc. 16th Coastal Engineering Conf., Hamburg, pp.268-284. 
Hulsbergen, C.H., 1974. Origin, effect and suppression of secondary waves. Proc. 14th Coastal Engineering Conf., Copenhagen, pp.392-411.

Huntley, D.A., 1980. Electromagnetic flow meters in nearshore field studies. In: Workshop on Instrumentation for Currents and Sediments in the Nearshore Zone, National Research Council of Canada, Associate Committee for Coastal Erosion and Sedimentation, Ottawa, Ont., pp.47-60.

Inman, D.L. and Bagnold, R.A., 1963. Littoral processes. In: M.N. Hill (Editor), The Sea, Vol. 3. Wiley-Interscience, New York, N.Y., pp.529-533.

Inman, D.L. and Frautschy, J.D., 1966. Littoral processes and the development of shorelines. Proc. Coastal Engineering Speciality Conference, Santa Barbara, Calif., pp.511536.

Jonsson, I.G., 1980. A new approach to oscillatory rough turbulent boundary layers. Ocean Eng., 7: 109-152.

Seymour, R.J. and King Jr., D.B., 1982. Field comparisons of cross-shore transport models. J. Waterway, Port, Coastal and Ocean Div., 108: 163-179.

Symonds, G. and Huntley, D.A., 1980. Waves and currents over a nearshore bar system. Proc. Canadian Coastal Conf., Natl. Res. Council Can., pp. 64-78.

Thornton, E.B., 1979. Energetics of breaking waves within the surf zone. J. Geophys. Res., 84: 4931-4938.

Thornton, E.B., Galvin, J.J., Bub, F.L. and Richardson, D.P., 1974. Kinematics of breaking waves. Proc. 15th Coastal Engineering Conf., Honolulu, Hawaii, pp.461-476.

Truxillo, S.G., 1970. Development of a resistance-wire wave gauge for shallow-water wave and water level investigations. Unpublished manuscript, Coastal Studies Institute, Louisiana State University, Baton Rouge, La.

Van de Graaf, J. and Tilmans, W.M.K., 1980. Sand transport by waves. Proc. 17th Coastal Engineering Conf., Sydney, N.S.W.

Wells, D.R., 1967. Beach equilibrium and second-order wave theory. J. Geophys. Res., 77: 497-504.

Wright, L.D., Chappell, J., Thom, B.G., Bradshaw, M.P. and Cowell, P., 1979. Morphodynamics of reflective and dissipative beach and inshore systems: Southeastern Australia. Mar. Geol., 32: 105-140.

Wright, L.D., Guza, R.T. and Short, A.D., 1982. Dynamics of a high-energy dissipative surf zone. Mar. Geol., 45: 41-62. 